\title{
Mobilizing crop diversity for climate change adaptation and resilience: Field experiences from Africa
}

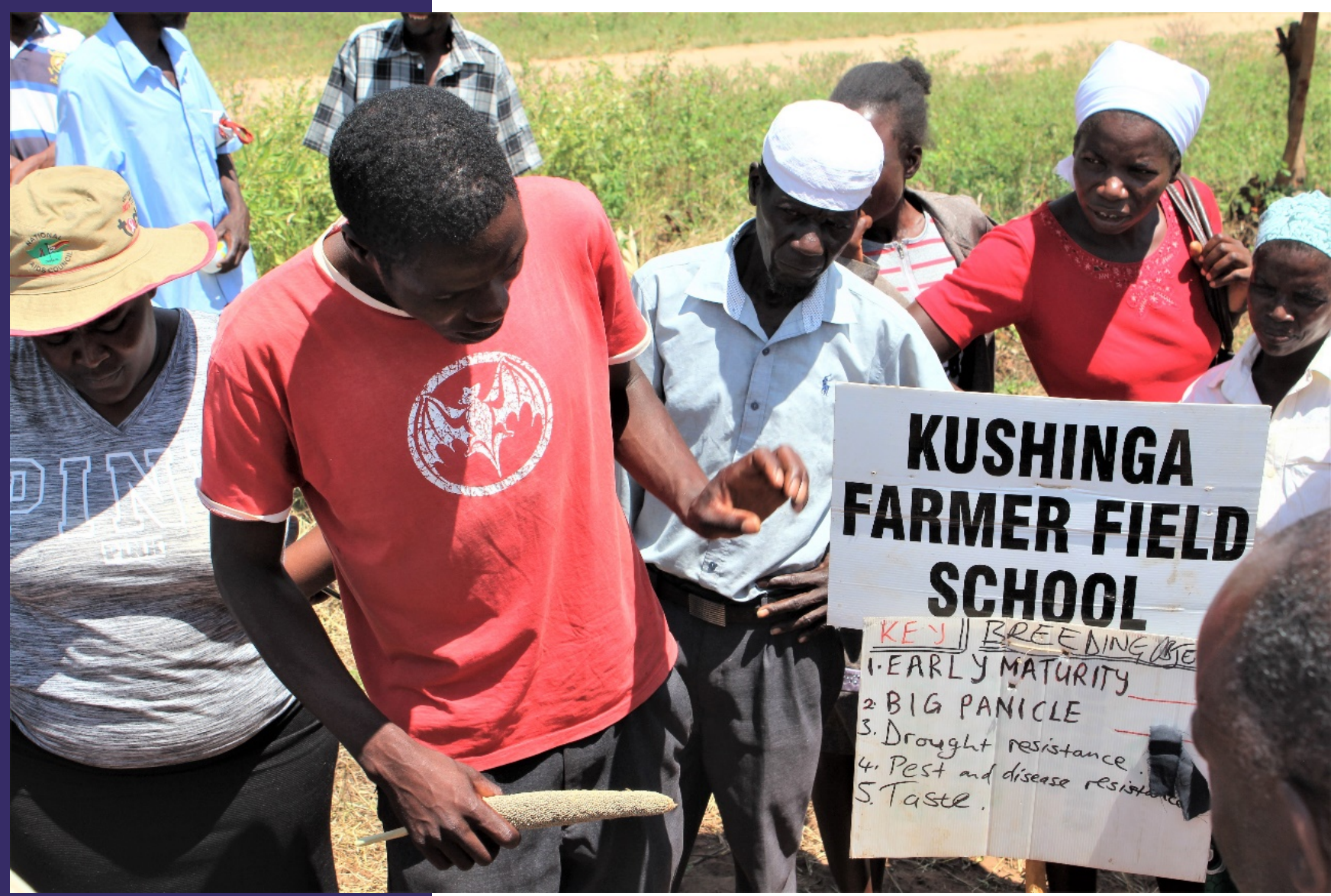

With contributions from:

Ronnie Vernooy, Joyce Adokorach, Harouna Coulibaly, Carlo Fadda, Manata Jeko, Ronald Kakeeto, Patrick Kasasa, Jonathan Sikitu Kazungu, Sipiwe Mapanda, Margaret Mollel, John Wasswa Mulumba, Andrew Mushita, Desterio Nyamongo, Gloria Otieno, Tobias Recha, Amadou Sidibe, Geoffrey Simiu, Bernard Wanjala, Patrick Wahome, and L'Équipe de L'Institut des Sciences Agronomiques du Burundi 
Ronnie Vernooy, Joyce Adokorach, Harouna Coulibaly, Carlo Fadda, Manata Jeko, Ronald Kakeeto, Patrick Kasasa, Jonathan Sikitu Kazungu, Sipiwe Mapanda, Margaret Mollel, John Wasswa Mulumba, Andrew Mushita, Desterio Nyamongo, Gloria Otieno, Tobias Recha, Amadou Sidibe, Geoffrey Simiu, Bernard Wanjala, Patrick Wahome, and L'Équipe de L'Institut des Sciences Agronomiques du Burundi

\section{ISSD Africa Working Paper, September 2021}

ISSD Africa 2021-3

\section{Acknowledgements}

We acknowledge the financial support provided by the Integrated Seed Sector Development in Africa (ISSD Africa) 2019-2022 project and by the CGIAR Research Program on Climate Change, Agriculture and Food Security (CCAFS). CCAFS is carried out with support from the CGIAR Trust Fund and through bilateral funding agreements.

For details, please visit https://ccafs.cgiar.org/donors.

The views expressed in this document cannot be taken to reflect the official opinions of these organizations.

This report can be downloaded for free at https://doi.org/10.18174/553632

(cc) BY-NC Creative Commons Attribution 4.0 (Netherlands) license. To view a copy of this license, visit https://creativecommons.org/licenses/by-nc/4.0/ 


\section{Authors}

Introduction: climate change, crop diversity and resilience Ronnie Vernooy, the Alliance of Bioversity International and CIAT

Diversity fields, seed diversity fairs and community seed banks: participatory agrobiodiversity management for adaptation to climate change in Mali

Amadou Sidibe and Harouna Coulibaly, L'Institut d'Economie Rurale (IER), Mali, with Ronnie Vernooy, the Alliance of Bioversity International and CIAT

La diversification pour combattre les changements climatiques au Burundi: des variétés des cultures autochtones pour la résilience

L'Équipe de L'Institut des Sciences Agronomiques du Burundi (ISABU)

New varietal diversity for climate change adaptation: bean, finger millet and sorghum in Kenya, Uganda and Tanzania

Gloria Otieno ${ }^{1}$, Tobias Recha1, Joyce Adokorach², John Wasswa Mulumba ${ }^{2}$, Ronald Kakeeto ${ }^{3}$, Patrick $W_{\text {Whome }}^{4}$, Desterio Nyamongo ${ }^{4}$, Jonathan Sikitu Kazungu ${ }^{5}$, Margaret Mollel 6 and Carlo Fadda ${ }^{1}$

1 The Alliance of Bioversity International and CIAT, 2 National Agricultural Research Organisation (NARO), Uganda, 3 Bulindi Zonal Agricultural Research and Development Institute, Hoima, Uganda, 4 Kenya Agricultural and Livestock Research Organization (KALRO), Kenya, 5 Tanzania Agricultural Research Institute, Dodoma, Tanzania, ${ }^{6}$ Tanzania Plant Genetic Resources Centre

Farmer Field Schools on participatory plant breeding in Zimbabwe: basis for improved food and nutrition security

Manata Jeko, Sipiwe Mapanda, Patrick Kasasa and Andrew Mushita, Community Technology

Development Trust

The importance of Community Seed Banks in Zimbabwe: the experiences of Community Technology Development Trust

Manata Jeko, Sipiwe Mapanda, Patrick Kasasa and Andrew Mushita, Community Technology

Development Trust

Constraints to agricultural development: how to maintain soil health and agrobiodiversity? Experiences from Bumula Subcounty, Bungoma, Kenya

Geoffrey Simiu and Bernard Wanjala, Sustainable Agricultural Development Initiatives

Improving and diversifying planted forages through selection, breeding and inclusion in local production systems -Examples of South-South learning

Michael Peters, Solomon Mwendia, Valheria Castiblanco, Rein van der Hoek, Stefan Burkart, Sabine Douxchamps, Uwe Ohmstedt and An Notenbaert, the Alliance of Bioversity International and CIAT

Final reflections

Ronnie Vernooy, the Alliance of Bioversity International and CIAT 


\section{Contents}

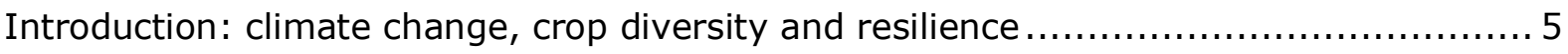

Diversity fields, seed diversity fairs and community seed banks: participatory agrobiodiversity management for adaptation to climate change in Mali......................... 7

La diversification pour combattre les changements climatiques au Burundi: des variétés

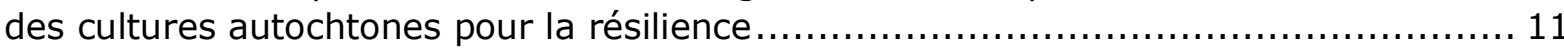

New varietal diversity for climate change adaptation: bean, finger millet and sorghum in

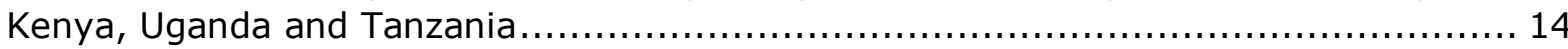

Farmer Field Schools on participatory plant breeding in Zimbabwe: basis for improved

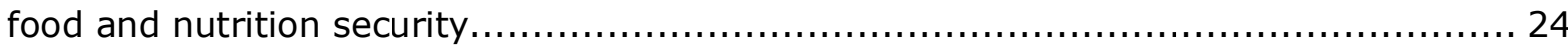

The importance of Community Seed Banks in Zimbabwe: the experiences of Community Technology Development Trust

Constraints to agricultural development: how to maintain soil health and agrobiodiversity? Experiences from Bumula Sub-county, Bungoma, Kenya

Improving and diversifying planted forages through selection, breeding and inclusion in

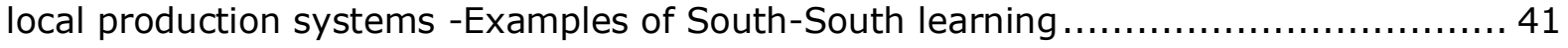

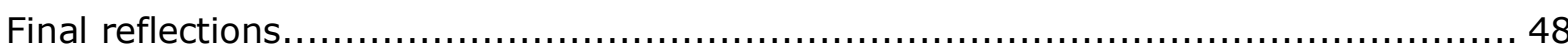




\section{Introduction: climate change, crop diversity and resilience}

Ronnie Vernooy, the Alliance of Bioversity International and CIAT

Across Africa, erratic and less predictable rainfall, higher temperatures, heat spells, and recurring droughts are predicted to become more frequent. This is leading to a change of cropping seasons and growing cycles and occurrence of new pests and diseases. As a result of these irregularities and uncertainties, farmers can no longer rely on crops and crop varieties that used to do well, with negative impacts on nutrition and food security and the capacity of farmers to withstand shocks. It is expected that climate change will reduce agrobiodiversity.

Farmers we meet and work with all over the world give us the same message: having better access to crop and varietal diversity helps them to adapt to climate change. Increased access to inter and intracrop genetic diversity may provide farmers an opportunity to switch to crops that are more resilient under new conditions, e.g. they may switch from maize to millet in rain-stressed areas. Farmers may also switch to varieties of the same crop that are better adapted to their local situation.

In most agricultural farming systems, farmers continue to rely to a very large degree on farmer managed seed systems. They depend on their own farm-saved seed, community seed saving practices, social seed exchange and seed purchased at nearby markets or from petty vendors. Improved varieties do not always reach farmers. Improved varieties can also often not compete with the local diversity, which is better adapted to the harsh conditions and local needs in many agricultural environments in Africa.

However, the potential of local diversity is not always well understood, and with rural populations becoming older and youngsters migrating to urban areas, knowledge on agrobiodiversity is disappearing. The implications as well as opportunities of the feminization of agriculture on agrobiodiversity and local seed systems are not clear yet. Although some international and regional seed and seed related agreements exist (e.g. the Convention on Biological Diversity (CBD) and the Nagoya Protocol to the $\mathrm{CBD}$, the International Treaty on Plant Genetic Resources for Food and Agriculture (ITPGRFA), and the Common Market for Eastern and Southern Africa (COMESA) national seed harmonization agreement under the COMESA Seed Harmonization Implementation Plan (COMSHIP) ${ }^{1}$, national governments and key agricultural organizations (e.g. NARS, gene banks, universities), as key actors in seed sector development, often have limited capacity to implement these agreements.

Other policy and legal challenges also exist: how to develop effective and fair regulatory systems for smallholder access to benefits derived from the use of genetic resources? Moreover, the space for multistakeholder collaboration and exchange of germplasm and related knowledge at national and regional levels is often limited.

In recent years, a number of international initiatives have piloted various forms of support for novel configurations of actors to work together to conserve and use agrobiodiversity in sustainable agricultural production systems and to equitably share benefits derived from those activities. These configurations operate at farm, community, national and international levels. Among these initiatives, Bioversity International (now the Alliance of Bioversity International and CIAT) and partners have researched the effectiveness of using agrobiodiversity, in particular in the form of crop and crop variety diversity, as an adaptive practice.

The hypothesis informing this research is that crop diversification can result in positive livelihood outcomes, such as food and nutritional security, income generation and good health. These outcomes, in turn, could lead to (increased) resilience of rural households and communities to environmental, socioeconomic and climatic shocks. In this working paper, we present a number of case studies that to a certain extent have "delivered" on this impact pathway. The case studies were compiled during the year 2020, the year that COVID-19 spread across the globe with devastating consequences for countries, communities and households everywhere.

\footnotetext{
${ }^{1}$ See, https://www.comesa.int/seven-comesa-states-have-harmonized-seed-regulations/
} 


\section{Synopsis of the theory of diversification}

Agroecology teaches that diversity among and within species serves as insurance or buffer against environmental upheaval. In an agroecological system, different species and varieties occupy different niches and respond differently to change, which results in more predictable aggregate community or ecosystem properties (Altieri et al., 2015, Attwood et al., 2017). In general, there are many more species than there are functions, which creates redundancy in the agroecosystem. Species diversity thus acts as a buffer against failure. In this way, agrobiodiversity fosters ecological resilience (Schroff and Ramos Cortés 2020).

Crop diversification is a practical application of this theoretical insight. It is the cultivation of different crop species and/or varieties spatially (mixed land use, intercropping) or temporally (rotations in different seasons). Crop diversity maintains the stability of food production, thus contributing to food security; contributes to dietary diversity and income generation, and reduces risks from climate variability, diseases, pests, and market changes. Farmers can practice crop diversification at the household level. However, farmers can also strengthen their capacity to access and use "new" diversity through community-based approaches, such as community-based biodiversity management by farmer groups, cooperatives and community seed banks.

While maintaining crop diversity on the farm and in the community is most often associated with riskcoping strategies, there are other potential benefits as well: optimal crop production under heterogeneous agroecological conditions in rainfed marginal areas; production of a variety of products for different uses; provision of commercial opportunities in multiple localities; self-consumption of crops with higher nutritional content, quality, and cultural significance, complementing foods purchased in markets; and, poverty reduction (Bellon et al. 2019). Crop diversification could also improve the management of other natural resources, such as (irrigation) water through the smart use of crop combinations that together are less water demanding (Watson, 2019). Furthermore, practicing crop diversification can also be a way to innovate in the face of climate change (UNU-IAS et al., 2014), e.g. introducing and evaluating promising new varieties of a crop.

\section{Case studies}

As part of the Integrated Seed Sector Development in Africa (ISSD Africa) program's activities for 2020, the Agrobiodiversity, seeds and climate change action learning group (Theme 3) sent out a call to various media to learn about inspiring examples of mobilizing agrobiodiversity for climate change adaptation along the lines of the above theory. The intention was to collect, compare and publish case studies from across Africa. The suggested outline:

\section{Background}

- $\quad$ Problem/opportunity addressed

- $\quad$ Research questions to be answered

- Theory of action/change

- Location(s) and actors involved

\section{Methodology}

- Methods and tools used

- Use of social and gender analysis (gender focused cases are welcomed)

- Activities carried out

\section{$\underline{\text { Results }}$}

- Compared to the theory of action/change

- Major outcomes, constraints and challenges

Conclusions and lessons learned

- Maximum 3,000 words excluding references

The cases received and accepted are presented in this chapter. 


\section{Diversity fields, seed diversity fairs and community seed banks: participatory agro-biodiversity management for adaptation to climate change in Mali}

Amadou Sidibe and Harouna Coulibaly, L'Institut d'Economie Rurale (IER), Mali, with Ronnie Vernooy, the Alliance of Bioversity International and CIAT

\section{Background}

Over the past three decades, agricultural areas in Mali have been affected by significant climate change, most notably increasing temperatures and a shortening of the rainy season. The effects of climate change and the growing population, which increases the demand for food, make the availability of sufficient food increasingly constrained. In this context, the availability of inter- and intra specific diversity could allow a substantial increase in agricultural production), contributing to more food and nutrition security (this was our main working hypothesis to develop proposals). The results reported here are those obtained from the execution of several projects on (the strengthening of) traditional crop and seed systems in the Ségou and Sikasso regions, and the sites of Bolimasso, Boumboro of the Prefecture of Tominian and Somo of the Prefecture of San, for many consecutive years between 2005 and 2019.

The targeted species were millet, sorghum, fonio and cowpeas, and, in recent years (2015-2019) also included a number of vegetables, in particular jute mallow and leaf amaranth. Research and development activities were combined, under the leadership of I'Institut d'Economie Rurale (IER) of Mali (under the Ministry of Agriculture), in collaboration with many national partners, international partners (e.g. FAO, SeedChange (formerly, USC Canada), and, more recently, the CGIAR Research Program on Climate Change, Agriculture and Food Security (CCAFS) and the CGIAR Research Program on Agriculture for Health and Nutrition (A4HN), Bioversity International (now the Alliance of Bioversity International and CIAT), with financial support of, notably, IFAD and the European Union.

\section{Activities}

Three key activities have been the implementation of diversity (seed) fields (photo 1), diversity (seed) fairs and (traditional) food fairs using participatory approaches for the management and conservation of local ecotypes, with a very strong involvement and participation of farmers and the recognition of their knowledge. This has made it possible to establish a local "forum" through which producers have access to seed of different crop varieties with different traits and growing cycles, ultimately resulting in the reduction of the negative effects of climate change. This example of the fields and fairs of diversity in Mali is exemplary.

Producers from the villages of Diagani Marka, Sokoro, Bogoro and Sadien who have been sufficiently trained, have appropriated the approach and continue with activities without external intervention since 2005 for the village of Sadien and 2006 for the others. Such actions conserve local ecotypes and disseminate improved varieties. These activities also created a feeling of trust among producers, strengthening mutual understanding and social cohesion -a form of community empowerment. 


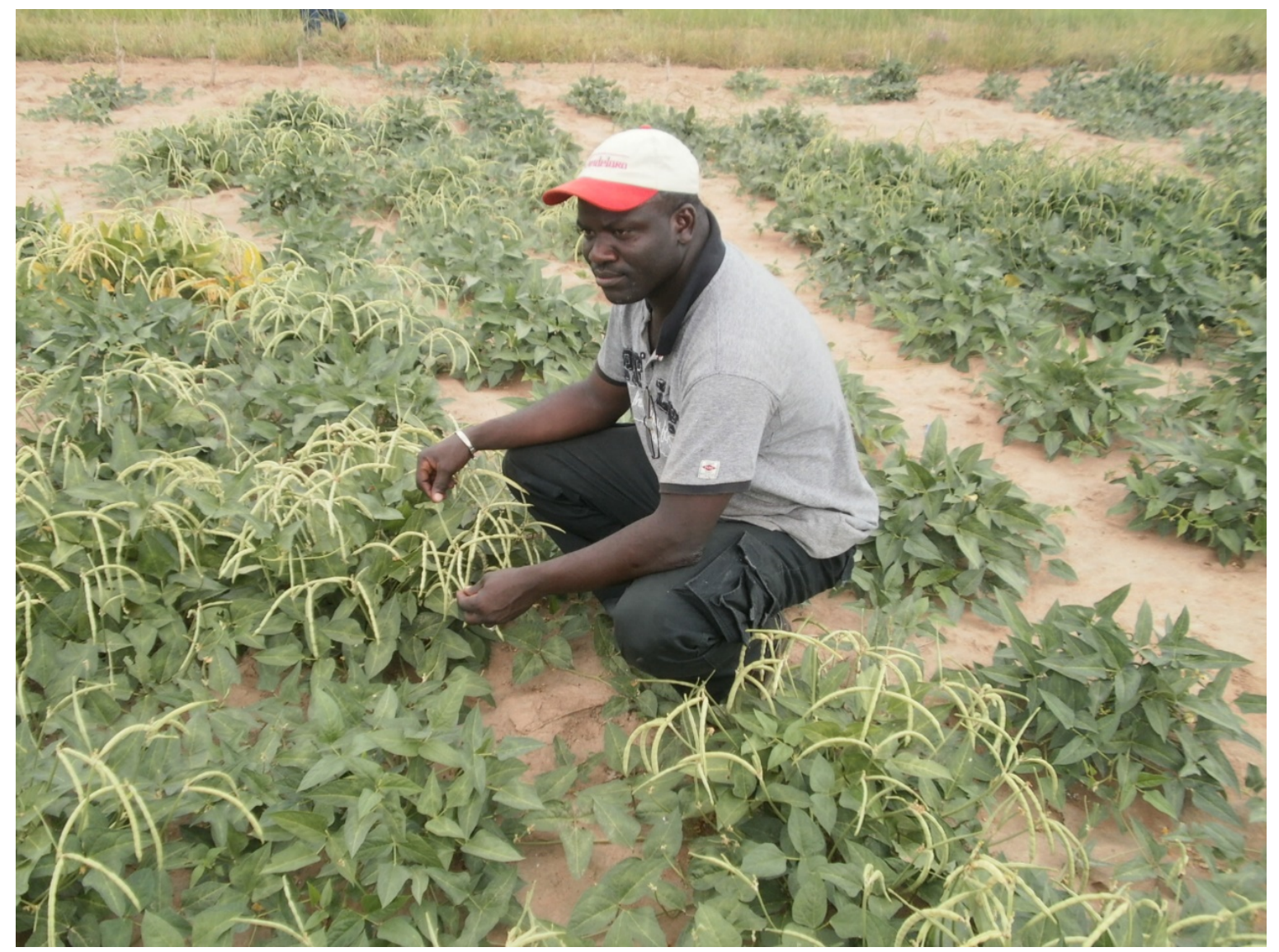

Photo 1: Cowpea diversity field, Mali. Credit: IER

Another key activity has been the establishment of community seed banks (CSBs). There are CSBs in Pètaka, Badiari, Gono (circle of Douentza); Fodokan and Socourani (circle of San) and Tassiga (circle of Ansongo). The participatory approach of seed banks was strengthened rooted in the in situ conservation project in Douentza and San where physical infrastructures were put in place with the participation/contribution of the various actors (labor provided by producers, other construction and equipment costs by the project, and monitoring and coordination of activities by the project technical team including researchers, developers of technical services and NGOs). These are initiatives of the farmers following the knowledge and experiences acquired through collaboration with URG/IER and its partners. The seven seed banks keep different types of crops and crop varieties. More than seven tons of seeds of different varieties were produced and then marketed and disseminated in different agricultural areas including San and Tominian. The seed/gene banks have effectively contributed to improving the access of producers to seed of different crops and crop varieties that are well appreciated in the diversity fields and at seed diversity fairs.

In the case of Somo village, seeds are given free of charge to members of the community seed bank. Anyone in the community can become a member by paying a nominal annual fee. Members sow the seeds, harvest and then give back to the seed bank double the quantity of seeds received in order to replenish stocks. The seed bank works on seed treatment, selection and planning of seed renewal and also on regeneration activities. This monitored, locally managed barter system both facilitates access to seed and ensures the renewal of seed stocks. It has made a great contribution to seed security of the members and their communities.

A fourth activity was the selection of improved varieties by local farmers with the support of the researchers. Women's preferences for varieties of different crops played an important role in the selection process. They are:

- Sorghum: white color of flour, consistency of tô (an important local dish resembling a cereal porridge, eaten as a main staple), taste of dishes, glossiness of the grain;

- $\quad$ Millet: porridge taste, grain -pale yellow, grain size;

- Fonio; ease of pillage, white color of grain, taste of dishes; ease of sale of grain and products;

- Cowpea: white color, market value, possibility of transformation into several menus. 
The following varieties were selected and retained by the farmers following several years of experimentation due to their stability of yield. In Bolimasso: millets Azozounou, Dounou, Doussoula and Toroniou C1, cowpea Korobalen; in Boumboro: millets Toroniou C1 and Kokinko, sorghums Babatassi and Sèguègnon and cowpea Korobalen; in Somo: Toroniou C1 millet, Jacoumbè sorghum and Niatia fonio. This is also demonstrated by the choice of the majority of these same varieties retained in the seed multiplication programs. Analysis of the results shows a higher frequency of improved varieties of Toroniou C1 millet, Jacumbè sorghum and Korobalen cowpea. These varieties have proven to be more suitable and meet the priority selection criteria of farmers. The farmers benefited from several training sessions allowing them to successfully establish a basic seed production scheme. Thus, six varieties of four species were successfully multiplied in the sites and seed was distributed among communities.

The above mentioned activities were complemented and strengthened by value chain development as a means to add value to local crops, diversify income sources, generate employment (in particular for women) and improve nutrition (Meldrum et al. 2020).

\section{Outcomes}

\section{Building human and social capital}

The participatory surveys and diagnostics carried out at the village level have made producers aware of the roles of local varieties, genetic erosion/loss of varieties and the need for their conservation. At the same time, the knowledge and awareness of farmer-producers technicians (extension agents) on the effects of climate change and adaptation measures and good practices increased significantly.

The involvement in the participatory research process strengthened the technical level of farmerproducers on rice cultivation techniques; and on the management of Bambara nut, cowpea, millet, and native vegetables. They also acquired new knowledge on the quality of seeds and especially where to find the information to obtain seed. Furthermore, farmer producers strengthened their knowledge about the control of vegetable pests with particular emphasis on the danger of unsafe use of pesticides on human health and the environment. In relation to genetic resources, the working capacity of extension agents through the provision of motorcycles and operational support, was strengthened.

The results of the research on crops and crop diversity improved the diet of farmer-producers based on the knowledge acquired on the nutritional role of vegetables; it also contributed to improving the food security of the population (not only paying attention to the economic role of crops, which is known by the farmer-producers). The work done also facilitated the establishment and consolidation of links between formal and informal local institutions that manage seed conservation and do seed multiplication, while also strengthening the flow of inter-village knowledge exchange as well as collective modes of action. Altogether, it reinforced a spirit of collaboration, solidarity and coherence in the villages; contributing to more social cohesion.

\section{Building natural capital}

Farmer producers benefitted from increased crop diversity and now have the possibility to choose different varieties of the crops they were already cultivating. In addition, they now produce "new" vegetable crops on certain sites where these important crops were not cultivated before. Through the research efforts, they succeeded to improve the yields of market garden crops (tomato, okra, eggplant, cabbage, pepper, shallot, onion, etc.) through the application of good agronomic practices taught and especially the use of good seeds provided by the IER. IER also facilitated the diffusion and adoption of rice varieties, cowpea, fonio and vegetable crops adapted with high yields.

The diversity field tests have led to the adoption of certain new varieties of rice; for the rainfed rice cultivation system: NERICA 4, DKP17 and DKA-P27; for the lowland rice cultivation system: DKA 1, DKA 21, DKA-M7 and BW348. The improved cowpea varieties Wilibali, Djiguiya, IT90-372-1-2, IT90-372-1-3, N'Ganashô were adopted because of their precocity (less than 80 days sowing to maturity) and their yield of more than one ton per hectare. They also adopted the tomato variety Tropimech, the okra varieties Fouroubani, Tiègan, Sabalibougou, Koni, Bendya and Keleya; the eggplant variety Jaxatu Guelevard; the Safi pepper variety; and the Violet de Galmi onion variety. In the community seed banks, there are now seed samples of hundreds of varieties. Overall, farmer producers have strengthened their capacity to adapt to climate change through this portfolio of diverse, early maturing and productive varieties appreciated by producers. It has led to increases in production and monetary income. 


\section{Sustainability}

The following factors will contribute to sustainability:

Creation of a 'platform' for exchanges between farmer-producers from the same village and from different villages through fields of diversity, food and seed fairs, and exchange visits.

- New knowledge and skills acquired by farmer-producers about good agricultural practices.

- The involvement of supervisory staff at the local and municipal levels.

- Provision of resilient varieties (better adapted to climate change).

- The adoption of novel techniques and seeds in the fields of market gardening and rice cultivation.

The use of participatory approaches involving the main actors of the agriculture sector (researchers, extension workers, development officials, farmer-producers) with an integration of modern and local knowledge and all actions are carried out on the basis of needs felt or expressed through participatory diagnostics.

The use of social and gender analysis has contributed to more support offered to the vulnerable groups (women and youth).

Policy uptake : the agricultural development policy of Mali is now focused on diversification. The key activities put in place by IER and partners align very well with this new policy. The results have contributed to improved seed and food security and adaptation to climate change -all key development goals of the country.

\section{References}

Meldrum, G., Sidibe, A., Padulosi, S. 2020. Promoting Bambara groundnut, fonio, and native vegetables for resilience and nutrition in Mali. Impact brief. Bioversity International, Rome and IER, Mali. https://hdl.handle.net/10568/109362

Sidibe, A. et al. 2018. Note de synthèse des activités des conventions de collaboration entre le projet D'accroissement de la productivité agricole du Mali (PAPAM) et I'Institut d'Economie Rurale (IER). IERURG-CPS (PAPAM)-Bioversity International-FIDA 2015-2018. IER, Sotuba, Mali 


\section{La diversification pour combattre les changements climatiques au Burundi: des variétés des cultures autochtones pour la résilience}

L'Équipe de L'Institut des Sciences Agronomiques du Burundi (ISABU)

\section{Contexte}

Dans les régions naturelles Imbo et Moso, de longues sécheresses sont à l'origine d'une diminution progressive des ressources en eau avec un tarissement des sources d'eau et une certaine tendance à la désertification (Ministère de I'Eau, de l'Environnement et de l'Aménagement du Territoire, 2013). Dans la région Imbo, la sécheresse entraîne une diminution de ressources en eau et une chute de la production agricole. Les fortes pluies provoquent de fortes érosions et des inondations dans la plaine de I'Imbo en contre-bas, suivies des destructions d'infrastructures socio-économiques dont les routes et les bâtiments.

Dans la région des plateaux centraux, il y a une tendance à l'allongement des saisons sèches allant de cinq à six mois. Le début tardif de la saison pluvieuse et la fin précoce de celle-ci sont à l'origine de la perturbation des saisons culturales et du dessèchement des cultures. La sécheresse a causé le tarissement d'un nombre considérable de points d'eau potable alors que les pluies trop abondantes provoquent des inondations avec des pertes importantes de production agricole dans les marais.

Il s'agissait d'évaluer et proposer les meilleures variétés des cultures autochtones dans les conditions des régions naturelles à faible précipitations (Moso et Imbo). Les activités ont été réalisées par I'ISABU en collaboration avec certaines Organisations Non-Gouvernementales (I'Union pour la Coopération et le Développement - Appui au Monde Rural [UCODE] et Adventist Development and Relief Agency [ADRA]). Cinq Communes ont été choisies pour l'expérimentation : il s'agit de trois Communes dans la région naturelle du Moso à savoir Cendajuru, Gisuru et Kinyinya et deux Communes de la région Imbo (Buganda et Rugombo).

L'activité a commencé en de 2015 à 2019, il y'a eu expérimentation sur le taro, l'igname, le niébé, le pois cajan et le sorgho dans deux régions. Les variétés utilisées sont issues des collections de I'ISABU (germoplasme local) conservées dans la banque des gènes et chaque culture contenait sept variétés, donc variétés 35 en total.

Toutes les variétés testées ont présenté des bons rendements et ont été proposées à la vulgarisation. Elles ont été ensuite soumises à l'homologation en tant que variétés coutumières. Les paysans ont opéré le choix de variétés à retenir selon certains critères: I'aspect végétatif (ténacité face à l'absence des pluies, la précocité, le rendement, le goût, etc.). Toutes les variétés ont présenté un aspect végétatif acceptable et une tolérance avérée à la sècheresse qui se répète dans ces régions.

Des associations d'agriculteurs et des producteurs pilotes ont été formés sur l'industrie semencière et ont été enregistrés par I'Office National de Contrôle et de Certification de Semences (ONCCS) en tant que producteurs des cultures traditionnelles après leur homologation. Cette étape a permis que ces cultures traditionnelles soient rependues sur plusieurs régions pour leur rusticité et une connotation non marginalisée dans la filière semencière au Burundi (photo 2).

Comme ces cultures et variétés étaient presque disparues au pays durant plus de deux décennies, leur vulgarisation massive nécessitait une dégustation organisée à l'intention des différents cadres et les agriculteurs pour évaluer les aliments traditionnels sur leur utilité nutritionnelle et sa contribution pour la lutte contre la faim au Burundi. 


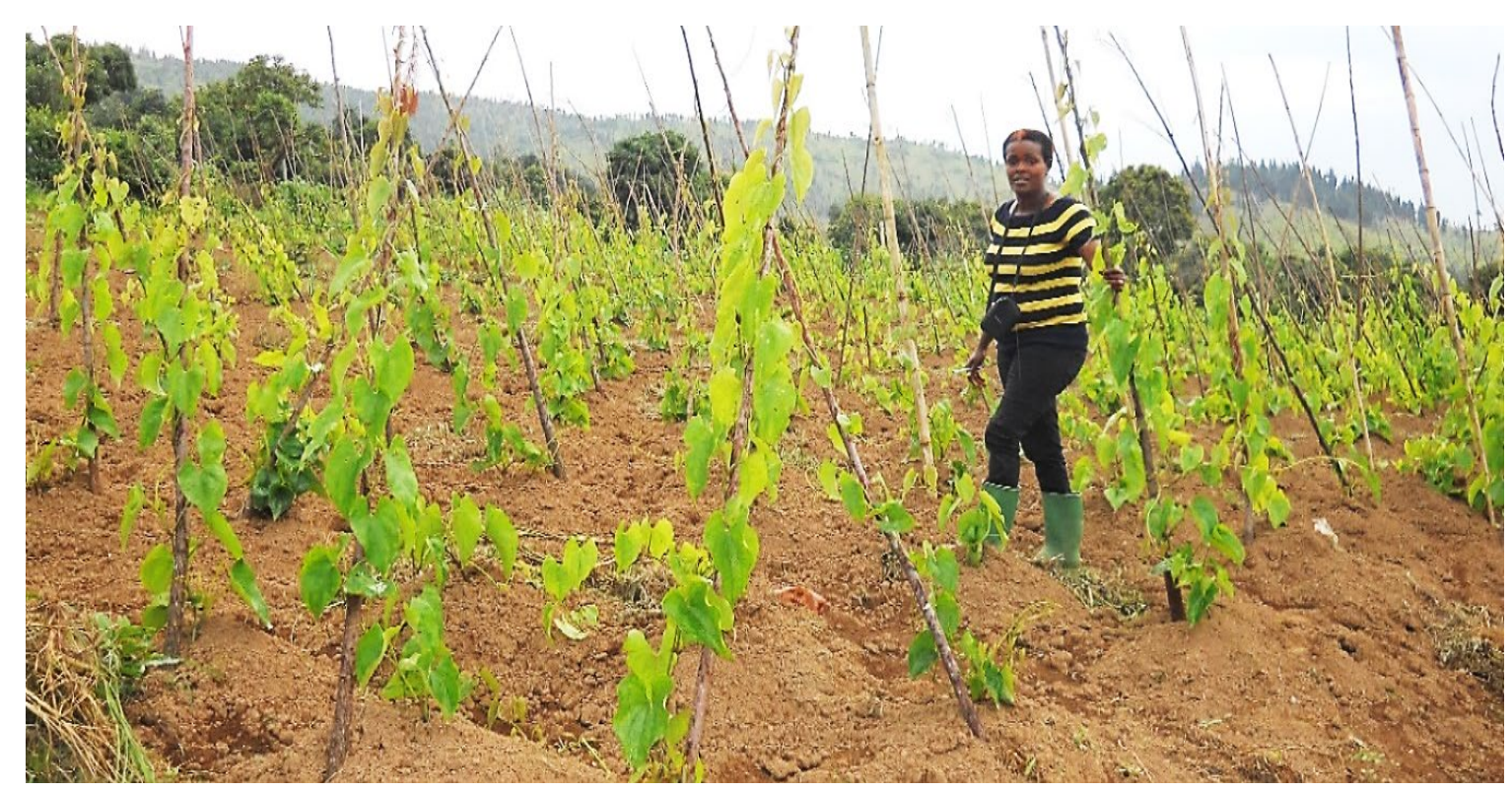

Photo 2: Champ de multiplication des semences d'igname en Commune Cendajuru (Moso) pour la résilience à la sécheresse. Credit: ISABU

\section{Resultats}

Elle a contribué à la diversification des variétés locales productives pouvant trouver un marché dans les industries agro-alimentaires locales. La promotion de ces cultures a fait partie des stratégies permettant d'augmenter la production pour pallier à des disettes cycliques dues aux variations du climat et le faible revenu des ménages. La région naturelle de Moso est actuellement caractérisée par la diversité des cultures à haute capacité de couverture du sol. Nous apprenons par l'approche de recherche-action que la population est capable d'orienter l'avenir de leur agriculture et consolidation de de la notion de conservation de la biodiversité.

Cette technique est liée à l'utilisation des cultures ou des variétés adaptées à la sécheresse. Ces cultures et variétés peuvent être précoce ou être capables de survivre dans des conditions de déficit hydrique. Certaines des variétés/cultivars utilisées pour faire face aux changements climatiques au Burundi ont été améliorés d'autres sont des variétés locales qui ont été utilisées de génération en génération par les producteurs locaux et constituent les cultures « indigènes ».

Ces cultures indigènes sont principalement composées d'ignames, de taro, de pois cajan, de niébé du sorgho et bien d'autres cultures légumières. Elles sont couramment cultivées dans presque toutes les régions naturelles, mais à des échelles différentes suite aux conditions agro climatiques de chaque région.

Bien que moins productifs que les variétés améliorées dans les conditions de bonne aptitude, les variétés locales présentent plusieurs avantages (photos 3-4): i) du fait de leur rusticité, elles continuent à fournir une production acceptable dans les zones marginales où les variétés améliorées n'auraient pas pu produire ; ii) les agriculteurs possèdent une large connaissance sur ces variétés et leur consommation est bien ancrée dans leurs habitudes alimentaires en outre' iii) elles ont des avantages nutritionnels et peuvent contribuer à augmenter la fertilité des sols. En effet, ces cultures ont été choisis car elles fournissent une solution aux contraintes nutritionnelles, économiques, agronomiques et environnementales. 

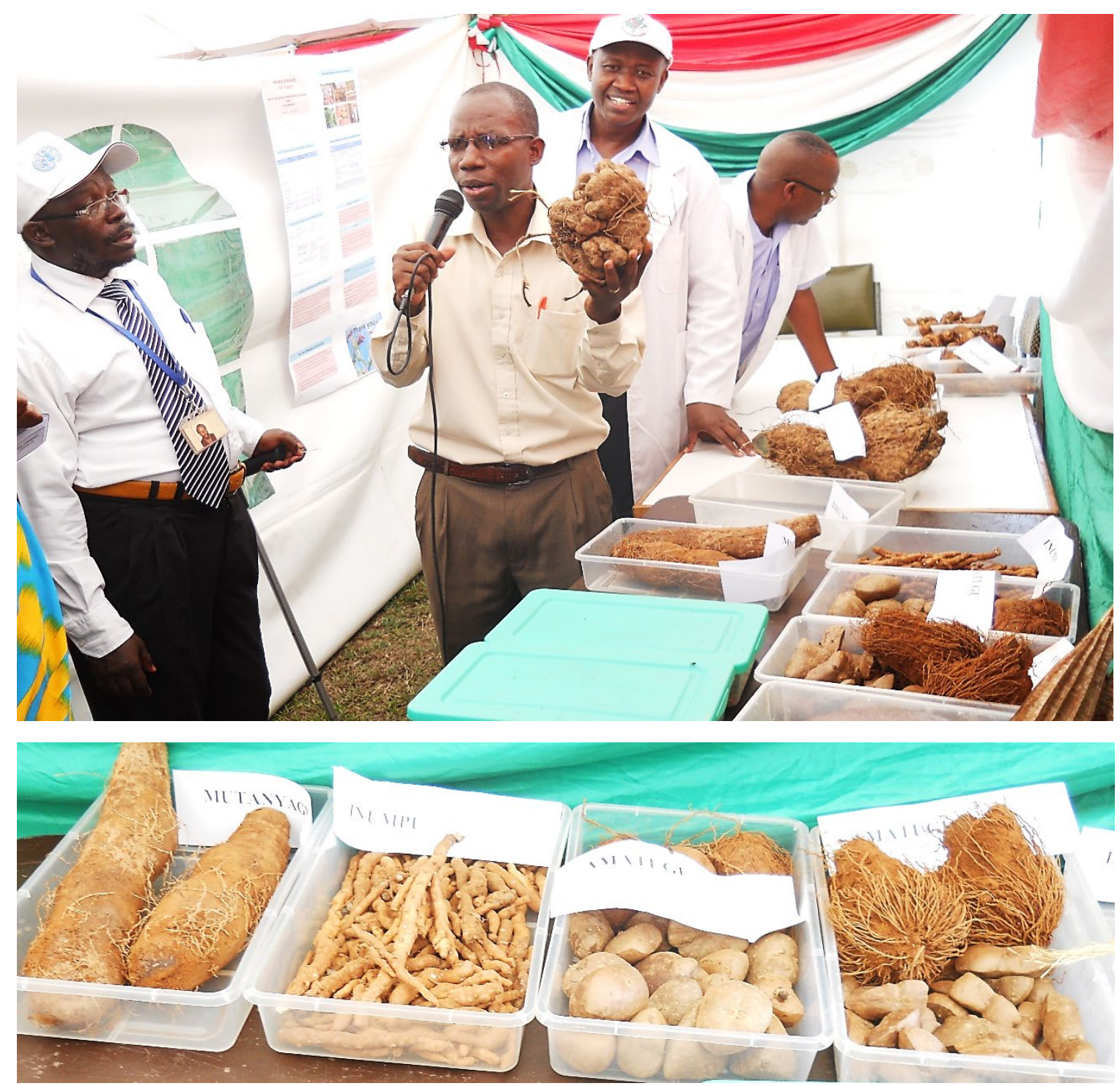

Photos 3-4: Exposition des cultures traditionnelles résilientes à la sécheresse. Credit: ISABU.

\section{References}

Ministère de l'Eau, de I'Environnement et de I'Aménagement du Territoire, 2013 


\section{New varietal diversity for climate change adaptation: bean, finger millet and sorghum in Kenya, Uganda and Tanzania}

Gloria Otieno1, Tobias Recha1, Joyce Adokorach², John Wasswa Mulumba², Ronald Kakeeto ${ }^{3}$, Patrick Wahome ${ }^{4}$, Desterio Nyamongo ${ }^{4}$, Jonathan Sikitu Kazungu ${ }^{5}$, Margaret Mollel ${ }^{6}$ and Carlo Fadda ${ }^{1}$

1 The Alliance of Bioversity International and CIAT

2 National Agricultural Research Organisation (NARO), Uganda

3 Bulindi Zonal Agricultural Research and Development Institute, Hoima, Uganda

${ }^{4}$ Kenya Agricultural and Livestock Research Organization (KALRO), Kenya

5 Tanzania Agricultural Research Institute, Dodoma, Tanzania

6 Tanzania Plant Genetic Resources Centre

\section{Background}

Climate change poses a serious and ever growing threat to the food and nutrition security of resource poor farmers globally. In Kenya, Tanzania and Uganda, climate change has led to increased pests and diseases, low agricultural productivity, food insecurity and general loss of genetic diversity. As a result, farmers have a very narrow gene pool on which they depend. One of the International Panel for Climate Change (IPCC's) strategies for climate change adaptation is introducing new crop diversity through plant breeding and other interventions.

To address these challenges, the Alliance of Bioversity International and CIAT in collaboration with several partners implemented two projects. The first project, "Promoting Open Source seed systems (OSSS) for beans, sorghum and Finger millet for climate change adaptation in Kenya, Uganda and Tanzania" was funded by the Food and Agriculture Organization of United Nations (FAO) Benefit Sharing Fund and ended in October 2019.

The project introduced and increased availability and diversity of climate-smart varieties of beans, finger millet and sorghum through testing, participatory breeding and production of high-quality seeds in four sites in Kenya, Uganda and Tanzania. It also increased access to a wider range of locally adapted varieties and established and community seed banks for conservations and marketing channels to disseminate the most promising varieties.

The Alliance implemented this project together with partners from the National Plant Genetic Resources Centre (NPGRC - Tanzania), National Agricultural Research Organization's Plant Genetic Resources Centre (NARO-PGRC-Uganda), The Genetic Resources Research Institute (GeRRI) of Kenya Agricultural Research and Livestock Organization, Hivos, and Sustainable Agriculture and Natural Resource Management Africa (SANREM-AFRICA). The project had these main elements:

- Identification of potentially adaptable materials from the three national gene banks i.e. the multilateral system (MLS) of access and benefit sharing and their exchange using Standard Materials Transfer Agreements (SMTAs)

- Testing and evaluation of genetic diversity of the above exchanged materials for useful and desired traits for climate change adaptation

- Dissemination of varieties of sorghum, millet and beans for climate change adaptation

- Capacity enhancement for in-situ conservation through community seed banking;

- Influencing an enabling policy environment for open source seed systems (Otieno 2018)

To build on the progress and outcomes of the Open Source Seed Systems project, a second project titled 'Upscaling climate smart and nutrition sensitive seed value chains for food and nutrition security in Uganda and Ethiopia' which is funded by the Netherlands Organization for Scientific Research (NWO) aims to improve farmers' adaptation to climate change and enhance food and nutrition security by increasing the availability of quality, diverse and adapted seeds within local communities through innovative and gender sensitive value chains. 
The Alliance is implementing this project with the KIT Royal Tropical Institute of the Netherlands, National Agricultural Research Organization's Plant Genetic Resources Centre (NARO-PGRC-Uganda), Bulindi Zonal Agricultural Research and Development Institute of the National Agricultural Research Organization (NARO-BUZARDI, Uganda), Participatory Ecological and Land Use Management (PELUMUganda) and Mekele University Ethiopia.

\section{Research process and steps}

Figure 1 depicts the research cycle and eight steps used by the research team.

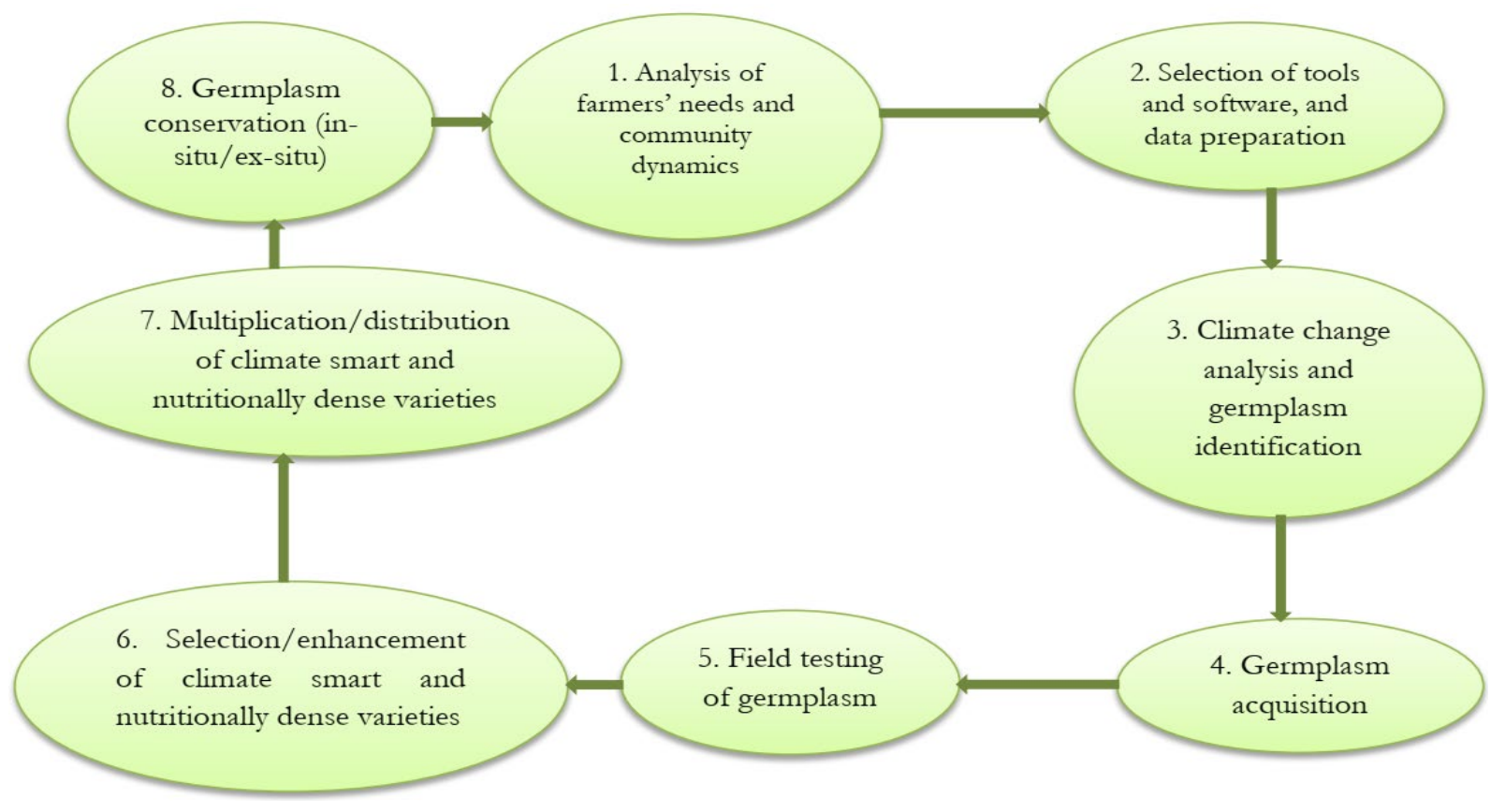

Figure 1: The research cycle and steps

The research started with identifying challenges of the community using a baseline survey. Then germplasm was selected from national genebanks using climate and GIS profiling, which was done by modelling the crop accessions that had GIS information. Genebanks were contacted to acquire those accessions through the Standard Material Transfer Agreement (SMTA) of the International Plant Treaty (ITPGRFA). The acquired accessions were then multiplied, and later subjected to field-testing through participatory variety selection and also through crowdsourcing with farmers in the three countries. For crowdsourcing, three cycles in Uganda, two in Kenya and Tanzania were done with over 2000 farmers. After selection, the varieties are now in the process of being disseminated through various avenues. Seeds are also being conserved in situ through community banks that are also working closely with the national genebanks.

\section{Results}

\section{Diversity and social seed networks}

In Uganda, a wide range of diversity existed within the community: 15 varieties of beans, 5 of millet, and 4 of sorghum were identified during focus group discussions. However, due to climate change and related challenges, this diversity had been decreasing over time, resulting in the loss of four bean varieties. The remaining diversity was being threatened due to climate uncertainties. Farmers were relying on four varieties of beans, two of sorghum, and two of millet, which could withstand drought and erratic rainfall. The analysis of seed exchange networking among farmers revealed that networks of female farmers were stronger than those of male farmers (Figure 2). The higher total mean betweenness in networks of female workers was 0.26 , compared to 0.21 in networks of male farmers. This indicated that more women were connecting with each other and with other actors, creating longer chains of seed exchange. 

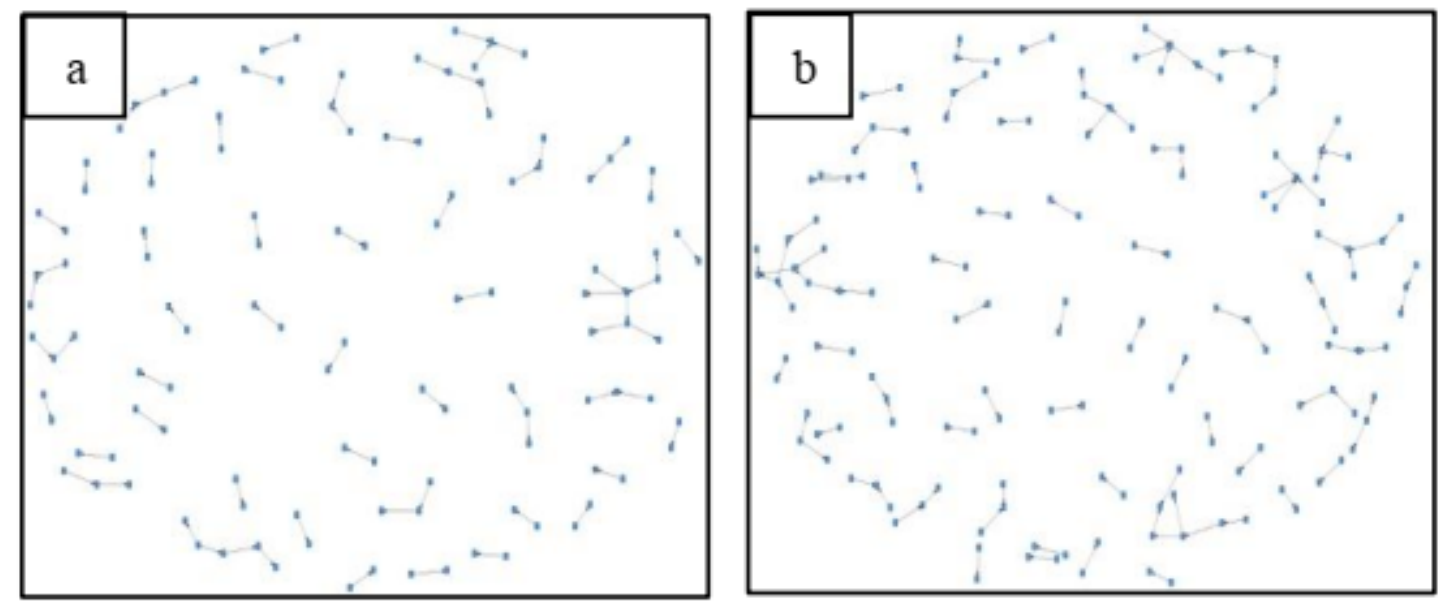

Figure 2: Seed exchange among male (a) versus female (b) farmers in Uganda

The same analysis in Tanzania revealed that networks of female farmers were stronger than those of male farmers (Figure 3). The higher total mean betweenness in networks of female farmers was 2.04 compared to those of male farmers $(0.62)$ indicating that more women were connecting actors, creating longer chains of seed exchange.
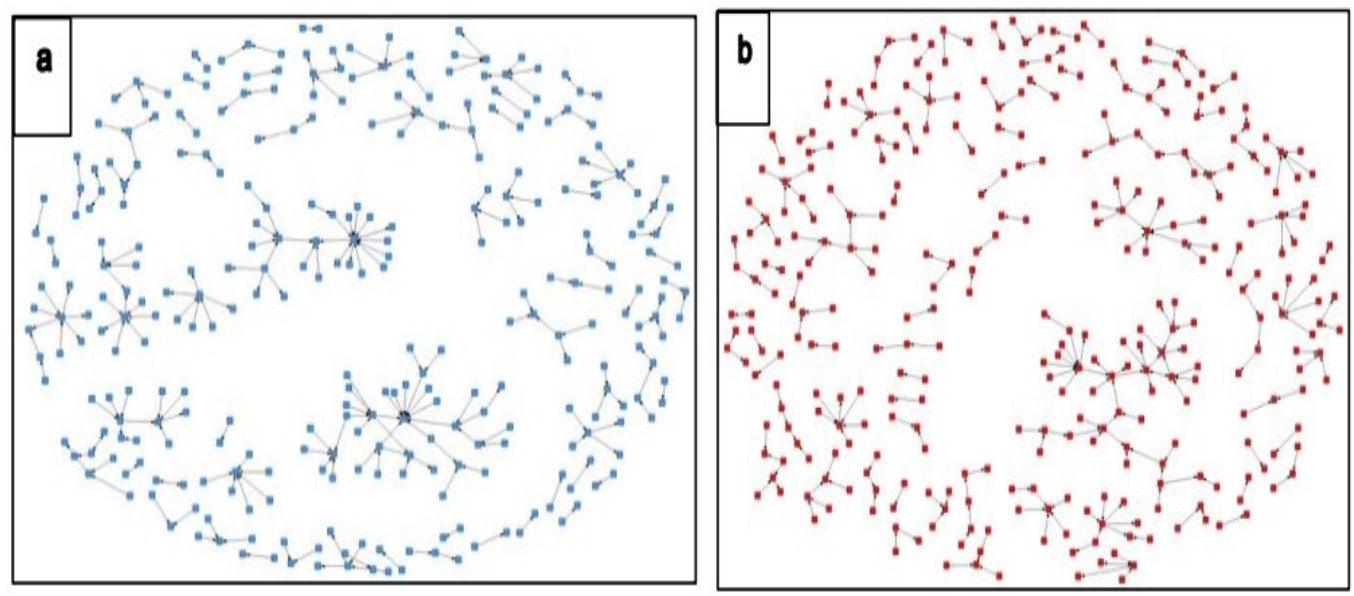

Figure 3: Seed exchange among male (a) and female (b) farmers in Tanzania

The level of diversity of crops in Nyando, Kenya, consisted of 13 varieties of sorghum, 6 of millet, and 6 of bean. Of these, three varieties of sorghum, one variety of millet, and two

varieties of bean were used for climate change adaptation. The networks of seed exchange among farmers revealed that networks of female farmers were stronger than those of male farmers. There was higher total mean betweenness values in networks of female farmers (30.3) compared to those of networks of male farmers (4.3) indicating that more women were connecting to each other and creating longer chains of seed exchange than men.

\section{Participatory variety selection and crowdsourcing results}

Over 500 accessions of five key crops were evaluated by over 2000 farmers in Kenya, Uganda and Tanzania for important traits for climate change adaptation. This "basket" of crop diversity included materials from the national genebanks of Kenya, Uganda and Tanzania. In Uganda, 63 bean and 44 millet varieties were evaluated. 
In Tanzania, 24 sorghum varieties. In Kenya, 52 finger millet and 49 sorghum varieties. The evaluation was done through crowdsourcing trials (baby trials) and on-station trials (mother trials) with local checks against the introduced varieties under rainfed conditions. Through on-station and crowdsourcing trials, farmers were able to select the best performing varieties. In Uganda, farmers selected 7 top performing bean and 7 finger millet accessions. In Tanzania, they selected 10 varieties and in Kenya, 10 finger millet and 10 sorghum varieties. Some of the selected varieties came from neighboring countries as shown in figures $4 \mathrm{~A}, 4 \mathrm{~B}$ and $4 \mathrm{C}$.
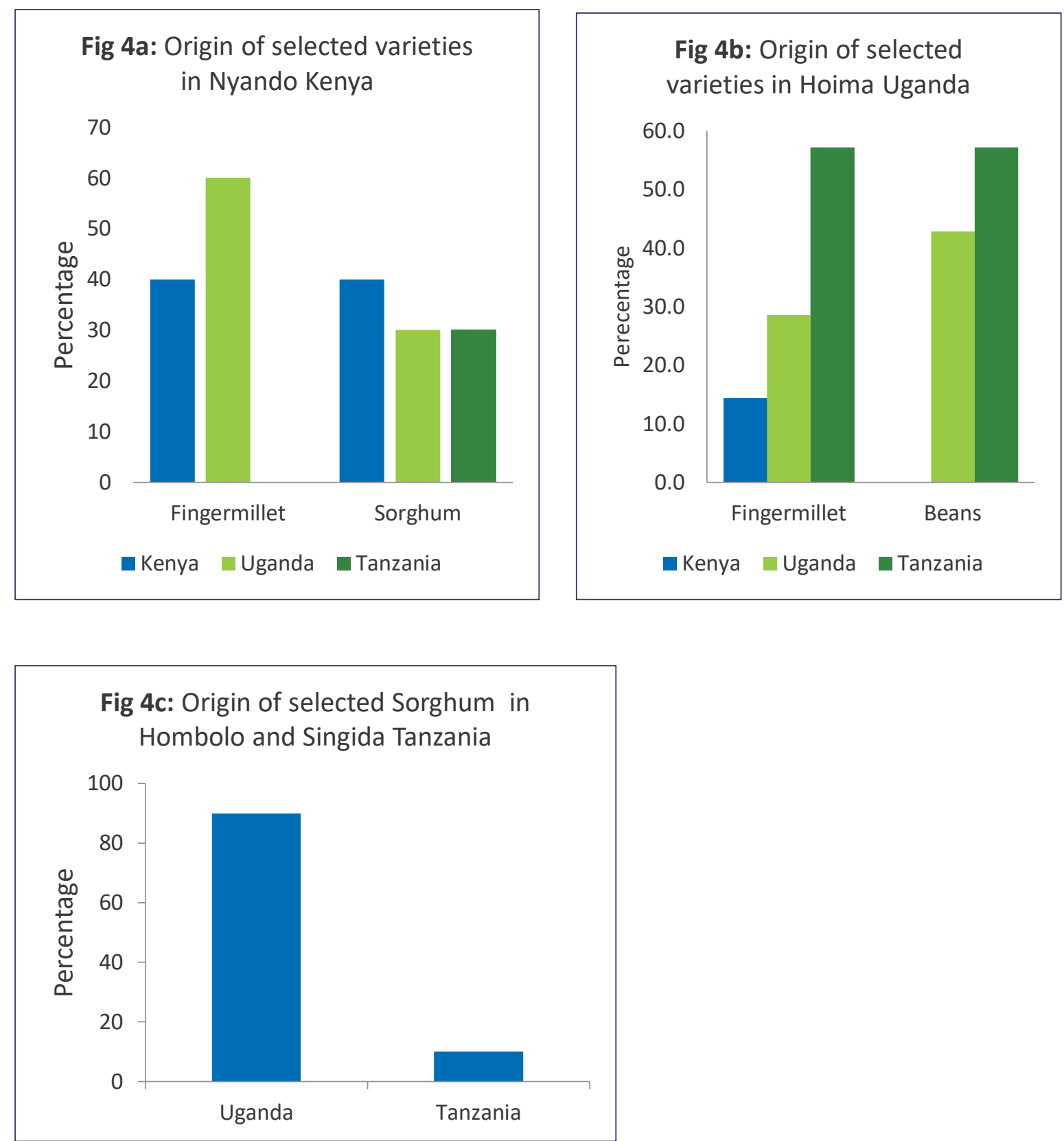

Figures 4A, 4B \& 4C: The percentage of selection varieties in each site in Kenya, Uganda and Tanzania and the country of origin of the selected varieties. The results indicated that introduction of new materials from different countries combined with successfully testing them with farmers provided farmers an opportunity to access more materials that can potentially shield them from total crop failure due to climatic stresses, such as extended droughts, short rainy seasons and emergence of new pests and diseases. 


\section{Nutritional and dietary information of selected varieties}

The selected varieties in Kenya, Uganda and Tanzania were taken to the Food and Nutritional Evaluation Laboratory (FANEL) within the Nutrition and Food Safety Platform, Biosciences eastern and central Africa (BecA) at the International Livestock Research Institute (ILRI) in Nairobi, Kenya, to analyze their nutritional compositions and the potential health benefits to farmers.

The results are shown in tables 1, 2 and 3. In bean varieties (Table 1), the iron content varied significantly and ranged from 6.55 to $8.34 \mathrm{mg} / 100 \mathrm{~g}$ with TZA 3165 scoring highest. According to Beebe et al. (2000), the average iron concentration in bean is $55 \mu \mathrm{g} / \mathrm{g}$. The zinc content among the bean varieties ranged between 2.53 to $3.19 \mathrm{mg} / 100 \mathrm{~g}$ with TZA 4174 scoring highest. Their calcium content ranged from 129.31 to $228.94 \mathrm{mg} / 100 \mathrm{~g}$. UNGB 2364 and TZA 4174 scored the highest calcium content with 228.54 and $228.94 \mathrm{mg} / 100 \mathrm{~g}$, respectively. Beans are an important source of iron and zinc, among other minerals (Torres et al. 2020). Total phenolic content was highest in TZA $3100(17.70 \%)$ and ranged from 6.72 to $17.70 \mathrm{mg} / 100 \mathrm{~g}$. This result aligns with the findings of Ariza-Nieto et al. (2007), who obtained a phenolic content range of 11.7 to $14.7 \mathrm{mg} / \mathrm{g}$ in common bean.

Antioxidants lower the risk of diseases such as cancer, atherosclerosis, rheumatoid arthritis, inflammatory bowel disease and cataracts, by lowering the amount of free radicals in the body. They have antifungal, antibacterial and antiviral activities (Harborne and Williams 2000, Arun et al. 2009). In general, processing methods have the greatest influence in altering the genetically-determined phenolic content and composition.

Table 1: Total phenolic and selected mineral content in selected bean varieties based on dry weight basis (dwb)

\begin{tabular}{|c|c|c|c|c|c|}
\hline \multirow[t]{2}{*}{ Bean Varieties } & \multirow{2}{*}{$\begin{array}{l}\text { Testing } \\
\text { Location }\end{array}$} & \multirow{2}{*}{$\begin{array}{l}\text { Total Phenolics } \\
\text { (mg/100g) }\end{array}$} & \multicolumn{3}{|c|}{ Minerals (mg/100g) } \\
\hline & & & Iron & Zinc & Calcium \\
\hline TZA 3100 & Uganda & $17.70 \pm 0.9^{a}$ & $7.61 \pm 1.4^{a}$ & $2.79 \pm 0.3^{a b}$ & $209.99 \pm 4.3^{a}$ \\
\hline TZA 3165 & Uganda & $6.72 \pm 0.1^{\mathrm{e}}$ & $8.34 \pm 1.0^{a}$ & $2.53 \pm 0.3^{b}$ & $205.01 \pm 6.6^{\mathrm{ab}}$ \\
\hline TZA 3990 & Uganda & $10.10 \pm 0.3^{\mathrm{cd}}$ & $7.65 \pm 0.8^{a}$ & $3.17 \pm 0.0^{a}$ & $181.75 \pm 14.8^{b}$ \\
\hline KAITABAHURU & Uganda & $15.73 \pm 1.1^{\mathrm{ab}}$ & $7.40 \pm 0.9^{a}$ & $2.74 \pm 0.0^{\mathrm{ab}}$ & $129.31 \pm 8.5^{c}$ \\
\hline KYOBOTE & Uganda & $13.15 \pm 2.2^{b c}$ & $6.55 \pm 0.2^{a}$ & $2.75 \pm 0.3^{a b}$ & $151.77 \pm 5.3^{c}$ \\
\hline UNGB 2364 & Uganda & $7.83 \pm 1.3^{\text {de }}$ & $7.70 \pm 0.1^{\mathrm{a}}$ & $3.08 \pm 0.2^{a}$ & $228.54 \pm 14.2^{a}$ \\
\hline TZA 4174 & Uganda & $11.74 \pm 0.2^{c}$ & $6.88 \pm 0.3^{a}$ & $3.19 \pm 0.0^{\mathrm{a}}$ & $228.94 \pm 6.1^{a}$ \\
\hline
\end{tabular}

Values are mean \pm SD: Analysis of samples done in triplicates: Means that do not share a letter are

significantly different. 
Table 2: Total phenolic and selected mineral content in sorghum varieties based on dry weight basis $(\mathrm{dwb})$

\begin{tabular}{|c|c|c|c|c|c|}
\hline \multirow[t]{2}{*}{ Sample } & \multirow{2}{*}{$\begin{array}{l}\text { Testing } \\
\text { Location }\end{array}$} & \multirow{2}{*}{$\begin{array}{l}\text { Total Phenolics } \\
\text { (mg/100g) }\end{array}$} & \multicolumn{3}{|c|}{ Minerals (mg/100g) } \\
\hline & & & Iron & Zinc & Calcium \\
\hline GBK 44669 & Kenya & $23.11 \pm 0.8^{\mathrm{m}}$ & $6.30 \pm 0.4^{\mathrm{fghi}}$ & $2.39 \pm 0.1^{\text {cdefg }}$ & $106.80 \pm 2.6^{b}$ \\
\hline GBK 051843 & Kenya & $119.66 \pm 1.3^{e}$ & $5.36 \pm 0.4^{\text {ghijk }}$ & $2.20 \pm 0.1^{\text {defg }}$ & $103.04 \pm 4.9^{b}$ \\
\hline GBK 051855 & Kenya & $12.04 \pm 1.1^{\mathrm{n}}$ & $6.73 \pm 0.6^{\mathrm{fgh}}$ & $3.36 \pm 0.4^{b}$ & $132.25 \pm 4.7^{\mathrm{a}}$ \\
\hline GBK 051759 & Kenya & $10.27 \pm 0.7^{\text {no }}$ & $5.23 \pm 0.2^{h i j k}$ & $2.39 \pm 0.5^{\text {cdefg }}$ & $132.26 \pm 10.7^{a}$ \\
\hline GBK 051746 & Kenya & $9.43 \pm 0.3^{\text {no }}$ & $5.99 \pm 1.0^{\text {ghij }}$ & $2.77 \pm 0.2^{\text {bcdef }}$ & $24.89 \pm 2.3^{\text {def }}$ \\
\hline GBK 051737 & Kenya & $145.92 \pm 1.5^{c}$ & $10.40 \pm 0.2^{\mathrm{cd}}$ & $2.61 \pm 0.2^{\text {bcdefg }}$ & $82.88 \pm 6.5^{c}$ \\
\hline GBK 044672 & Kenya & $44.68 \pm 0.8^{\mathrm{kl}}$ & $4.75 \pm 0.1^{\mathrm{ijk}}$ & $2.66 \pm 0.4^{\text {bcdef }}$ & $106.55 \pm 3.9^{b}$ \\
\hline GBK 044626 & Kenya & $47.25 \pm 1.9^{k}$ & $4.04 \pm 0.4^{k}$ & $2.13 \pm 0.3^{\mathrm{efg}}$ & $21.16 \pm 1.5^{f}$ \\
\hline GBK 004251 & Kenya & $92.47 \pm 0.5^{f}$ & $4.26 \pm 0.6^{\mathrm{jk}}$ & $1.68 \pm 0.3^{g}$ & $25.71 \pm 3.2^{\mathrm{def}}$ \\
\hline GBK 051744 & Kenya & $157.79 \pm 1.7^{\text {no }}$ & $5.23 \pm 0.1^{h i j k}$ & $3.29 \pm 0.3^{\mathrm{bc}}$ & $80.78 \pm 2.4^{c}$ \\
\hline UNGB 65 & Tanzania & $173.60 \pm 1.2^{\mathrm{a}}$ & $7.94 \pm 0.6^{e f}$ & $2.50 \pm 0.3^{\text {bcdefg }}$ & $34.89 \pm 4.9^{d}$ \\
\hline UNGB 2752 & Tanzania & $127.84 \pm 1.6^{d}$ & $6.32 \pm 0.4^{\mathrm{fghi}}$ & $3.37 \pm 0.2^{\mathrm{b}}$ & $28.00 \pm 2.3^{\text {de }}$ \\
\hline UNGB 2841 & Tanzania & $62.62 \pm 2.6^{i}$ & $12.77 \pm 1.2^{b}$ & $3.05 \pm 1.0^{\text {bcde }}$ & $29.50 \pm 3.4^{\text {de }}$ \\
\hline UNGB 2796 & Tanzania & $94.86 \pm 2.7^{f}$ & $11.65 \pm 0.6^{b c}$ & $2.87 \pm 0.1^{\text {bcdef }}$ & $25.47 \pm 0.7^{\text {def }}$ \\
\hline UNGB 2777 & Tanzania & $76.94 \pm 2.8^{g}$ & $7.02 \pm 1.0^{\mathrm{fg}}$ & $2.95 \pm 0.2^{\text {bcde }}$ & $19.59 \pm 0.5^{\text {ef }}$ \\
\hline UNGB 2775 & Tanzania & $56.12 \pm 2.7^{j}$ & $6.58 \pm 0.1^{\mathrm{fgh}}$ & $2.96 \pm 0.1 \mathrm{bcde}$ & $21.74 \pm 0.3^{\text {def }}$ \\
\hline UNGB 2767 & Tanzania & $63.67 \pm 0.3^{i}$ & $7.77 \pm 0.9^{\mathrm{ef}}$ & $3.25 \pm 0.1^{b c}$ & $19.61 \pm 1.2^{\mathrm{ef}}$ \\
\hline UNGB 2742 & Tanzania & $69.07 \pm 1.7^{\mathrm{h}}$ & $8.83 \pm 0.2^{\text {de }}$ & $10.46 \pm 0.0^{a}$ & $29.80 \pm 1.9^{\text {de }}$ \\
\hline UNGB 2314 & Tanzania & $52.80 \pm 0.9^{j}$ & $6.34 \pm 0.2^{\mathrm{fghi}}$ & $3.10 \pm 0.1^{\mathrm{bcd}}$ & $23.66 \pm 1.8^{\text {def }}$ \\
\hline UNGB 2279 & Tanzania & $69.19 \pm 0.6^{h}$ & $15.11 \pm 0.4^{a}$ & $1.97 \pm 0.2^{\mathrm{fg}}$ & $29.37 \pm 0.8^{\mathrm{de}}$ \\
\hline Hakika & Tanzania & $7.16 \pm 0.6^{\circ}$ & $12.48 \pm 0.4^{b}$ & $2.90 \pm 0.2^{\text {bcdef }}$ & $23.19 \pm 1.7^{\text {def }}$ \\
\hline UNGB 2378 & Tanzania & $41.17 \pm 0.9^{1}$ & $12.04 \pm 0.2^{b c}$ & $2.66 \pm 0.0^{\text {bcdef }}$ & $31.61 \pm 2.2^{\mathrm{de}}$ \\
\hline
\end{tabular}

Values are mean \pm SD: Analysis of samples done in triplicates: Means that do not share a letter are significantly different.

Table 3: Total phenolics and selected minerals in finger millet samples (dwb)

\begin{tabular}{|c|c|c|c|c|c|}
\hline \multirow[t]{2}{*}{ Sample } & \multirow{2}{*}{$\begin{array}{l}\text { Testing } \\
\text { Location }\end{array}$} & \multirow{2}{*}{$\begin{array}{l}\text { Total Phenolics } \\
(\mathrm{mg} / 100 \mathrm{~g})\end{array}$} & \multicolumn{3}{|c|}{ Minerals $(\mathrm{mg} / 100 \mathrm{~g})$} \\
\hline & & & Iron & Zinc & Calcium \\
\hline TZA 1701 & Uganda & $14.87 \pm 0.1^{b}$ & $6.14 \pm 0.7^{b c}$ & $2.60 \pm 0.1^{\text {efgh }}$ & $392.25 \pm 7.0^{\text {defg }}$ \\
\hline TZA 1693 & Uganda & $8.16 \pm 0.4^{\text {de }}$ & $5.93 \pm 1.3^{b c}$ & $2.51 \pm 0.1^{\mathrm{fgh}}$ & $431.81 \pm 4.4^{\mathrm{cd}}$ \\
\hline TZA 3934 & Uganda & $5.94 \pm 0.9^{e}$ & $4.89 \pm 0.5^{b c}$ & $2.56 \pm 0.3^{\text {efgh }}$ & $400.67 \pm 21.0^{\text {defg }}$ \\
\hline TZA 3676 & Uganda & $6.98 \pm 0.9^{e}$ & $5.42 \pm 0.2^{\mathrm{bc}}$ & $2.80 \pm 0.2^{\text {cdefgh }}$ & $511.18 \pm 56.8^{a b}$ \\
\hline UNGB 4146 & Uganda & $6.88 \pm 0.9^{e}$ & $3.99 \pm 0.5^{c}$ & $2.72 \pm 0.2^{\text {defgh }}$ & $325.89 \pm 7.3^{g}$ \\
\hline UNGB 2321 & Uganda & $8.72 \pm 0.6^{\mathrm{de}}$ & $8.29 \pm 1.2^{b}$ & $2.20 \pm 0.0^{\mathrm{h}}$ & $519.53 \pm 7.7^{\mathrm{ab}}$ \\
\hline GBK 000920 & Uganda & $8.59 \pm 1.3^{\text {de }}$ & $8.04 \pm 0.8^{b}$ & $2.30 \pm 0.1^{\mathrm{gh}}$ & $389.96 \pm 11.6^{\mathrm{de}}$ \\
\hline GBK 057855 & Uganda & $12.64 \pm 1.3^{b c}$ & $6.44 \pm 0.8^{\mathrm{bc}}$ & $2.92 \pm 0.1^{\text {cdefg }}$ & $165.49 \pm 3.8^{f}$ \\
\hline GBK 043052 & Kenya & $14.20 \pm 2.1^{\mathrm{bc}}$ & $4.88 \pm 0.3^{b c}$ & $3.18 \pm 0.5^{\text {bcdef }}$ & $440.74 \pm 77.8^{\mathrm{bcd}}$ \\
\hline GBK 051721 & Kenya & $12.41 \pm 1.4^{\mathrm{bc}}$ & $6.17 \pm 0.3^{b c}$ & $3.40 \pm 0.2^{\mathrm{abcd}}$ & $347.89 \pm 9.5^{\text {efg }}$ \\
\hline GBK 051725 & Kenya & $18.30 \pm 1.8^{a}$ & $16.80 \pm 2.7^{a}$ & $3.92 \pm 0.2^{\mathrm{a}}$ & $425.95 \pm 22.7^{\mathrm{de}}$ \\
\hline GBK 051718 & Kenya & $18.84 \pm 0.6^{e}$ & $7.50 \pm 0.5^{\mathrm{bc}}$ & $3.09 \pm 0.2^{\text {bcdef }}$ & $433.44 \pm 7.0^{\mathrm{cd}}$ \\
\hline GBK 051717 & Kenya & $7.73 \pm 0.1^{\mathrm{e}}$ & $7.73 \pm 2.2^{\mathrm{bc}}$ & $3.93 \pm 0.2^{\mathrm{a}}$ & $412.88 \pm 1.5^{\text {def }}$ \\
\hline GBK 051705 & Kenya & $7.56 \pm 0.7^{\mathrm{e}}$ & $8.15 \pm 1.4^{b}$ & $3.65 \pm 0.3^{a b}$ & $343.58 \pm 11.5^{\mathrm{fg}}$ \\
\hline GBK 043275 & Kenya & $13.19 \pm 1.8^{b c}$ & $6.18 \pm 1.2^{\mathrm{bc}}$ & $3.46 \pm 0.3^{a b c}$ & $523.94 \pm 24.3^{a}$ \\
\hline GBK 043180 & Kenya & $11.25 \pm 0.4^{\mathrm{cd}}$ & $8.08 \pm 2.4^{b}$ & $2.60 \pm 0.1^{\text {efgh }}$ & $372.66 \pm 8.8^{\text {defg }}$ \\
\hline Chepyaliyet & Kenya & $9.01 \pm 1.0^{\mathrm{de}}$ & $5.33 \pm 0.3^{b c}$ & $3.21 \pm 0.1^{\text {bcde }}$ & $403.11 \pm 7.7^{\text {defg }}$ \\
\hline
\end{tabular}

Values are mean \pm SD: Analysis of samples done in triplicates: Means that do not share a letter are significantly different. 
In sorghum, the iron content in sorghum varieties ranged between 4.04 and $15.11 \mathrm{mg} / 100 \mathrm{~g}$ (Table 2) with UNGB 2279 ranking significantly higher than the other varieties. Their zinc content varied between 1.68 and $10.46 \mathrm{mg} / 100 \mathrm{~g}$ with UNGB 2742 significantly outscoring the other varieties. The calcium content of the sorghum varieties ranged between 19.59 and $132.26 \mathrm{mg} / 100 \mathrm{~g}$, in which GBK 051759 $(132.26 \mathrm{mg} / 100 \mathrm{~g})$ scored highest.

These results align with Saleh et al. (2013), who obtained a calcium concentration of $35.23 \mathrm{mg} / 100 \mathrm{~g}$ in sorghum. Among the sorghum varieties, total phenolic content was highest in UNGB $65(173.60 \%)$ and ranged between 7.16 and $173.6 \mathrm{mg} / 100 \mathrm{~g}$ among the 22 varieties analyzed. Sorour et al. (2017) obtained a higher concentration of between 178.28 and $825.36 \mathrm{mg} / 100 \mathrm{~g}$. Sorghum grain has been reported to have phenolic compounds that influence its sensory and nutritional quality (Hahn et al. 1984, Arun et al. 2009). Awika and Rooney (2003) and Arun et al. (2009) reported that sorghum phenols act as antioxidants in vitro. The phenolic profile of sorghum is different, more abundant and diverse compared to other common cereal grains (Xiong et al. 2019).

The iron content of the finger millet varieties ranged between 3.99 and $16.80 \mathrm{mg} / 100 \mathrm{~g}$ with GBK 051725 significantly scoring the highest. Siwela (2009) obtained iron concentrations of $3.3-14.89 \mathrm{mg} / 100 \mathrm{~g}$ in finger millet. This is in line with our findings. The zinc content of the finger millet varieties ranged from 2.20 to $3.93 \mathrm{mg} / 100 \mathrm{~g}$, with GBK 051717 scoring highest. Leder (2004) reported the iron content of finger millet as $36.6 \mathrm{mg} / 100 \mathrm{~g}$, which is significantly higher than our results $(3.99-16.80 \mathrm{mg} / 100 \mathrm{~g})$. The calcium content in the finger millet varieties ranged between 165.49 and $523.94 \mathrm{mg} / 100 \mathrm{~g}$, with GBK 043275 scoring the highest. These results are in line with Saleh et al. (2013), who obtained a mean calcium concentration of $348 \mathrm{mg} / 100 \mathrm{~g}$ in finger millet. The total phenolic content ranged from 5.94 to $18.84 \mathrm{mg} / 100 \mathrm{~g}$ with the highest contained in GBK 051718.

\section{Seed catalogues}

The research data were compiled in comprehensive seed catalogues (Otieno et al. 2020). The selected varieties are multiplied and further evaluated with the aim to be registered and released as quality declared seed. As a result, farmers have succeeded in producing considerable volumes of food in addition to strengthening their agronomic skills concerning seed, soil, water, plant and pest and disease management. Various breeding programs now have access to elite lines of sorghum, finger millet and bean that have various traits for climate change adaptation. Some elite lines with good traits have been identified; for example, a Striga resistant sorghum variety in Nyando, and some very high yielding bean and millet varieties. This information has been disseminated with the expectation that breeding programs will be able to take up some of these varieties and further improve them.

\section{Community seed banks}

Another key achievement was the establishment of two community seed banks that have already been launched (Recha et al. 2018). The Hoima community seed bank in Uganda is currently conserving 20 millet varieties and 32 bean varieties (photo 5). The Nyando community seed bank in Kenya is conserving 17 bean varieties, 15 millet varieties and 22 sorghum varieties (photo 6 ). A second seed bank, called Upper Nyando, is in the process of being established through (women) farmers' own initiative. They contributed money, rented land and multiplied seed on their own. Currently, they have rented a building where they are keeping their seed. In Uganda, the National Plant Genetic Resource is developing a seed bank data base that will contain information on all genetic resources conservation centers and community seed banks in the country, including tracking the exchange and movement of these resources across the communities. This will provide an overview to policy makers, academic institutions and researchers on the use and adaptability of these varieties, which they can use for better decision making. This database/platform is in its final stage.

Linkages with national breeding programs have been established. The Institute of Biotechnology and Research of Jomo Kenyattah University of Agriculture and Technology is linked to the farmers in Nyando and has been working with them on participatory variety selection and testing. In Hoima, the Bulindi Zonal Agricultural Research and Development Institute of Uganda's National Agricultural Research Organization, has been working with farmers on the participatory variety selection of beans and finger millet.

Two seed cooperatives have been registered to enable farmers produce Quality Declared Seed. Currently, farmers in Hoima are multiplying seed on a five acre farm. This seed will be sold under the auspices of their seed cooperative. There are seed custodian farmers who would also like to start producing seed and partner with DashCrop limited (in Kenya) and other private sector players. 

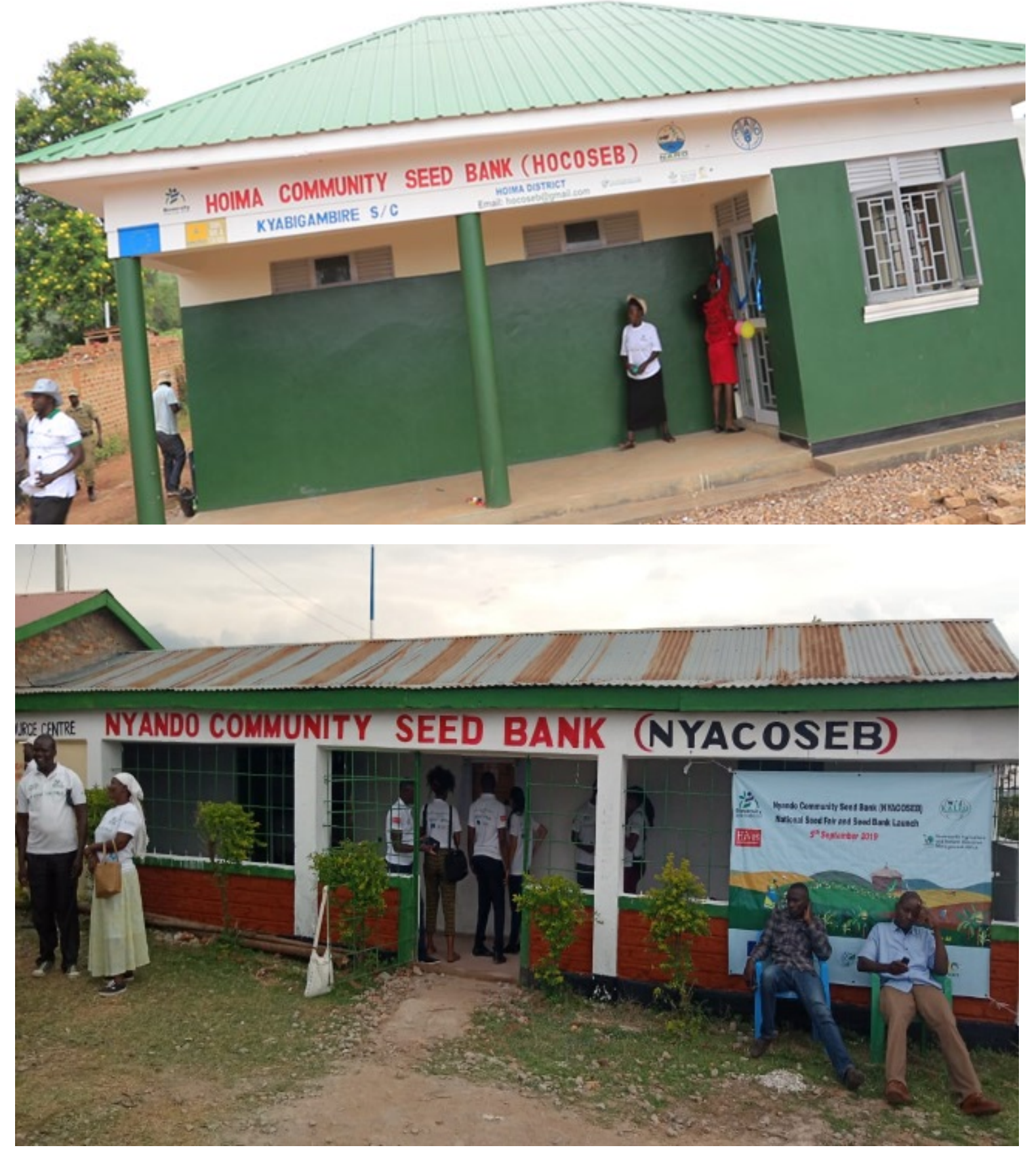

Photos 5 and 6: Hoima Community seed bank in Uganda (top) and Nyando community seed bank in Kenya (bottom). Credit: Alliance of Bioversity International and CIAT/T.Recha 


\section{Policy implications}

The social seed network analysis showed that farmers exchange seed among themselves, in particular done by women. In order to improve seed distribution, strategies that include expanding the accessibility of agricultural extension services and using organizations named by respondents as a source of seed and information could be used. Individuals identified as nodal farmers, i.e., having high total mean betweenness, could also serve as a distribution source for diverse and adapted seeds.

Community seed banks are used as a repository of new and improved varieties at local levels. These conservation efforts should be documented and the right mechanisms put in place to support the efforts of farmers engaged in such activities. For example, the selected varieties which are conserved in Nyando and Hoima community seed banks could be registered and commercialized as farmer varieties, using the QDS standards. In Kenya, the Alternative Seed Delivery System regulation could be adopted to commercialize such varieties by farmers through their seed banks and farmer groups.

For breeding purposes and sharing of benefits across the border, the participating national genebanks in Kenya, Uganda and Tanzania could develop additional conditions to the Standard Material Transfer Agreement originally used to exchange the seed. These conditions should clarify how access and benefits of the exchanged varieties will be managed according to national policies and laws. A number of policy discussions towards this have been (see: Otieno et al. 2018, Recha et al. 2018, Recha et al. 2019, and Otieno et al. 2020).

\section{References}

Ariza-Nieto M, Blair MW, Welch RM, Glahn RP (2007) Screening of iron bioavailability patterns in eight bean (Phaseolus vulgaris L.) genotypes using the Caco-2 cell in vitro model. Journal of Agricultural and Food Chemistry, 55(19), 7950-7956

Arun GK, Venkatesh R. Sosle GS, Vijaya R (2009) Nutritional and Rheological Properties of Sorghum, International Journal of Food Properties, 12:1, 55-69, DOI: 10.1080/10942910802252148

Awika JM, Rooney LW (2003) Screening methods to measure antioxidant activity of sorghum (Sorghum bicolor) and sorghum products. Journal of Agricultural and Food Chemistry, 51 (23), 6657-6662

Beebe S, Gonzalez AV, Rengifo J (2000) Research on trace minerals in the common bean. FoodNutr. Bull; 21:387-391.

Hahn DH, Rooney LW, Earp CF (1984) Tannins and Phenols of Sorghum. Cereal Foods World, 29 (12), 776-779

Harborne JB, Williams CA (2000) Advances in flavonoid research since 1992. Phytochemistry, 55 (6), 481-504

Léder I (2004) Sorghum and Millets. Cultivated Plants, Primarily as Food Sources, Encyclopedia of Life Support Systems (EOLSS), Developed under the Auspices of the UNESCO, Eolss Publishers, Oxford, UK, http://www.eolss.net

Otieno, G. (2018) Open source seed systems for climate change adaptation in Kenya, Uganda and Tanzania: Highlighting the importance of policy support. CCAFS Blog.https://ccafs.cgiar.org/blog/opensource-seed-systems-climate-change-adaptation-kenya-uganda-and-tanzaniahighlighting\#.W6kJhdczbIU

Otieno, G.; Westphal, I. (2018) Building resilience through "Open Source Seed Systems" for climate change adaptation in Kenya, Uganda, and Tanzania: What are the options for policy? 8 p. https://cgspace.cgiar.org/handle/10568/100157

Otieno, G.; Recha, T.; Vernooy, R.; Fadda, C.; Yosef, G.K.; Halewood, M. (2020) Report of a policy dialogue workshop on open source seed systems for climate change adaptation in East Africa. 19-22 November 2019, Entebbe, Uganda. Rome (Italy): Bioversity International. 36 p. ISBN: 978-92-9255193-3 https://cgspace.cgiar.org/handle/10568/110900

Otieno, G.; Recha, T.; Fadda, C.' Mulumba, J.; Adokorach, J.; Ahumuza, J.; Kakeeto, R.; Kairagura, G. (2020) Enhancing access to genetic resources for climate change adaptation in Kenya, Uganda and 
Tanzania: Seed catalogue of best performing varieties of beans and finger millet in Hoima Uganda. Rome (Italy): Bioversity International. https://hdl.handle.net/10568/111212

Recha J.; Mungai, C.; and Mutsami, C. (2018) The future of banking is in seeds: Hoima district establishes a community seed bank to strengthen farmers' adaptive capacity.

https://ccafs.cgiar.org/news/future-banking-seeds-hoima-district-establishes-community-seedbankstrengthen-farmers-adaptive\#.W6NX6ciFNPZ

Recha T, Muwanika C, Otieno G and De Jonge, B (2019) Report of the International Workshop on Registration of Farmers' Varieties, 4-7 December 2018, Entebbe, Uganda. Bioversity International, Rome and Oxfam Novib, The Hague. https://cgspace.cgiar.org/handle/10568/101227

Recha, T., Vernooy, R., Halewood, M., Otieno, G. (2019) Resilient seed systems for climate change adaptation and sustainable livelihoods in the East Africa subregion. Report of the consultative workshop, 5-8 March 2019, Entebbe, Uganda. Bioversity International, Rome, Italy https://cgspace.cgiar.org/bitstream/handle/10568/101278/Resilient Recha 2019 CF Nov2020.pdf?seq $\underline{\text { uence }=4 \& \text { isAllowed }=y}$

Siwela, M. (2009). Finger millet grains phenolics and their impact on malt and cookie quality. PhD thesis. (University of Pretoria) Retrieved from

http://repository.up.ac.za/bitstream/handle/2263/28784/02chapter2.pdf?sequence=3\&isAllowed=y

Sorour MA, Mehanni AE, Taha EM, Rashwan AK (2017) Changes of Total Phenolics, Tannins, Phytate and Antioxidant Activity of Two Sorghum Cultivars as Affected by Processing. Journal of Food and Dairy Sci., Mansoura Univ, Vol. 8 (7): $267-274$

Torres LCR, Amaral JPG, Canniatti-Brazaca SG (2020) Promoters effectiveness in the improvement in iron and zinc absorption from the rice and bean. Food Science and Technology, Epub February 03, 2020. https://doi.org/10.1590/fst.15419

Xiong Y, Zhang P, Warner DR, Fang Z (2019) Sorghum Grain: From Genotype, Nutrition, and Phenolic Profile to Its Health Benefits and Food Applications. Comprehensive Reviews in Food Science and Food Safety. Institute of Food Technologists $\AA$ doi: 10.1111/1541-4337.12506 


\section{Farmer Field Schools on participatory plant breeding in Zimbabwe: basis for improved food and nutrition security}

Manata Jeko, Sipiwe Mapanda, Patrick Kasasa and Andrew Mushita, Community Technology Development Trust

\section{Introduction}

Community Technology Development Trust (CTDT) has been collaborating with national and international breeding institutions (Zimbabwe's Crop Breeding Institute, CIMMYT and ICRISAT) to carry out Participatory Plant Breeding (PPB) in farmers' fields using the Farmer Field School (FFS) approach for over 15 years now. The focus has been on Participatory Variety Selection (PVS), Participatory Variety Enhancement (PVE) and Participatory Variety Development. Figure 5 shows the number of FFS plots established in farmers' fields in different districts over the years. The highest number of FFS (over 400) were established during the 2016/2017 and 2017/2018 agricultural seasons.

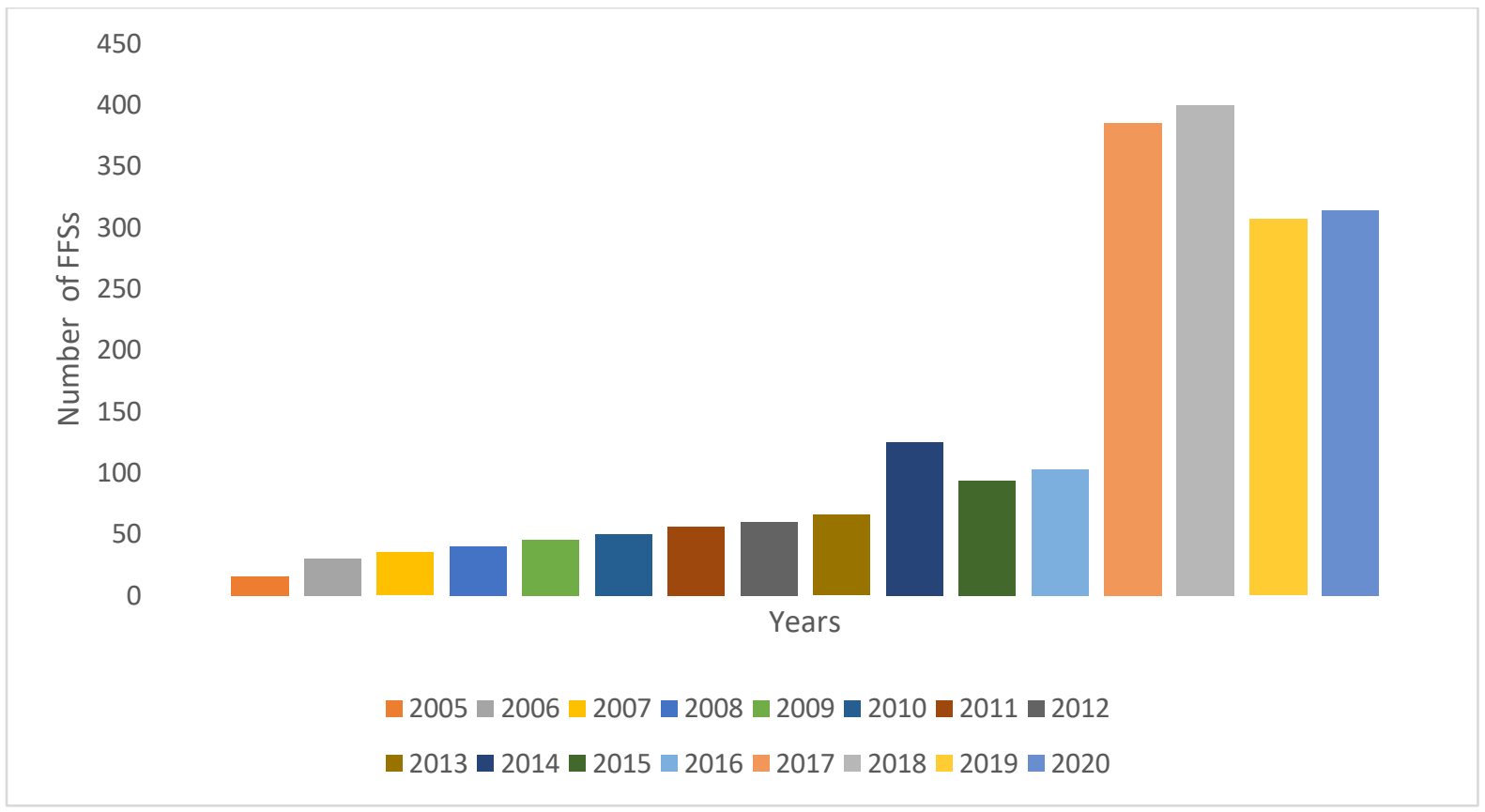

Figure 5: Number of Farmer Field Schools established by CTDT in Zimbabwe

\section{Theory of change}

The Agricultural Biodiversity programme of CTDT is based on the understanding that increasing crop diversity contributes to improved food and nutrition security at household level, including under conditions of climate change. With climate change induced droughts, there is a very high and increasing likelihood of harvest failure when farmers grow fewer crops and crop varieties. The more crop varieties a farmer plants in any season, the better his/her chances of harvesting something are, as some of the crops will reach physiological maturity even if the amount of rainfall received is below normal or if the rainfall distribution is poor.

Working with breeders from the National Crop Breeding Institute, CYMMTY and ICRISAT and staff from the National Gene Bank of Zimbabwe, CTDT has made significant efforts to increase the diversity of crops in farmers' hands in over 20 districts. This strategy was adopted after realizing that farmers are failing to obtain decent harvests, in particular in cropping seasons where total rainfall received is low or in cases where rainfall distribution is uneven. Due to the vigorous promotion of maize by the corporate seed sector in Zimbabwe, the majority of farmers, including those in districts where maize growing is 
not recommended, still plant maize. This has resulted in the country experiencing persistent food and nutrition insecurity, notably in low rainfall districts, the majority of which are located along Zimbabwe's boarders. Communities in these districts rely on food aid from the government, the World Food Programme and other development partners. Promotion of drought tolerant crops such as sorghum, pearl and finger millet, groundnut and cowpea can reduce chances of harvest failures. However, high yielding varieties of these crops are not readily available. There is little research done on these crops; there are very few releases of new varieties; and challenges related to their processing have not been addressed.

\section{Location(s) and actors involved}

Crop improvement initiatives are implemented in CTDT's sites in Mudzi, Tsholotsho, Mutoko, Murehwa, Chipinge, Rushinga and Uzumba Maramba Pfungwe districts. Except for Murehwa and parts of Chipinge, the rest of the districts are located in low rainfall agro-ecological regions of the country. In addition, the soils in these sites are of inherently low fertility. The following actors/institutions are involved in the implementation of activities:

- The National Gene Bank of Zimbabwe

- Departments of Agricultural, Technical and Extension Services (Agritex)

- Zimbabwe's National Crop Breeding Institute

- ICRISAT and CIMMYT

- Farmers and local government leaders in target districts

- Champion Farmer Seed Cooperative Company

\section{Methodologies used}

The following methodologies were employed in the implementation of projects to increase crop diversity at field level.

\section{Participatory Variety Selection (PVS)}

Farmers in CTDT's sites seek to access new genetic materials for use in their communities to be able to utilize varieties with traits defined in their breeding objectives that are not present in the varieties currently grown in the community. Farmers, through the FFS, try to identify such new breeding material. The breeding institutions, i.e. CIMMTY, ICRISAT and CBI, have been providing PVS materials of sorghum, groundnut, pearl millet, finger millet, cowpea, maize, chickpea and pigeon pea to farmers, who, together with with Agritex (government extension officers) and CTDT field staff, select stable lines based on the preferred characteristics identified by the FFS. The selection is carried out from a number of stable varieties (usually between six and ten). Farmers select lines with their preferred traits over two to three growing seasons and then retain seed of the most preferred lines. Results of these activities are passed on to the breeders who incorporate the results in their variety release proposals (photo 7). Using this approach, farmers working with CTDT, and with financial support from Oxfam, have contributed to the release of two improved sorghum varieties and two pearl millet varieties.

PVS has resulted in a substantial increase in crop diversity in the local communities, following the introduction of new varieties over a reasonably long period of time (Figure 6). In addition, farmers are now utilizing the new varieties to enhance their food and nutrition security, in particular under the prevailing effects of climate change. Some farmers who have been able to join the group of smallholder seed producers because of the knowledge gained in the FFS. 


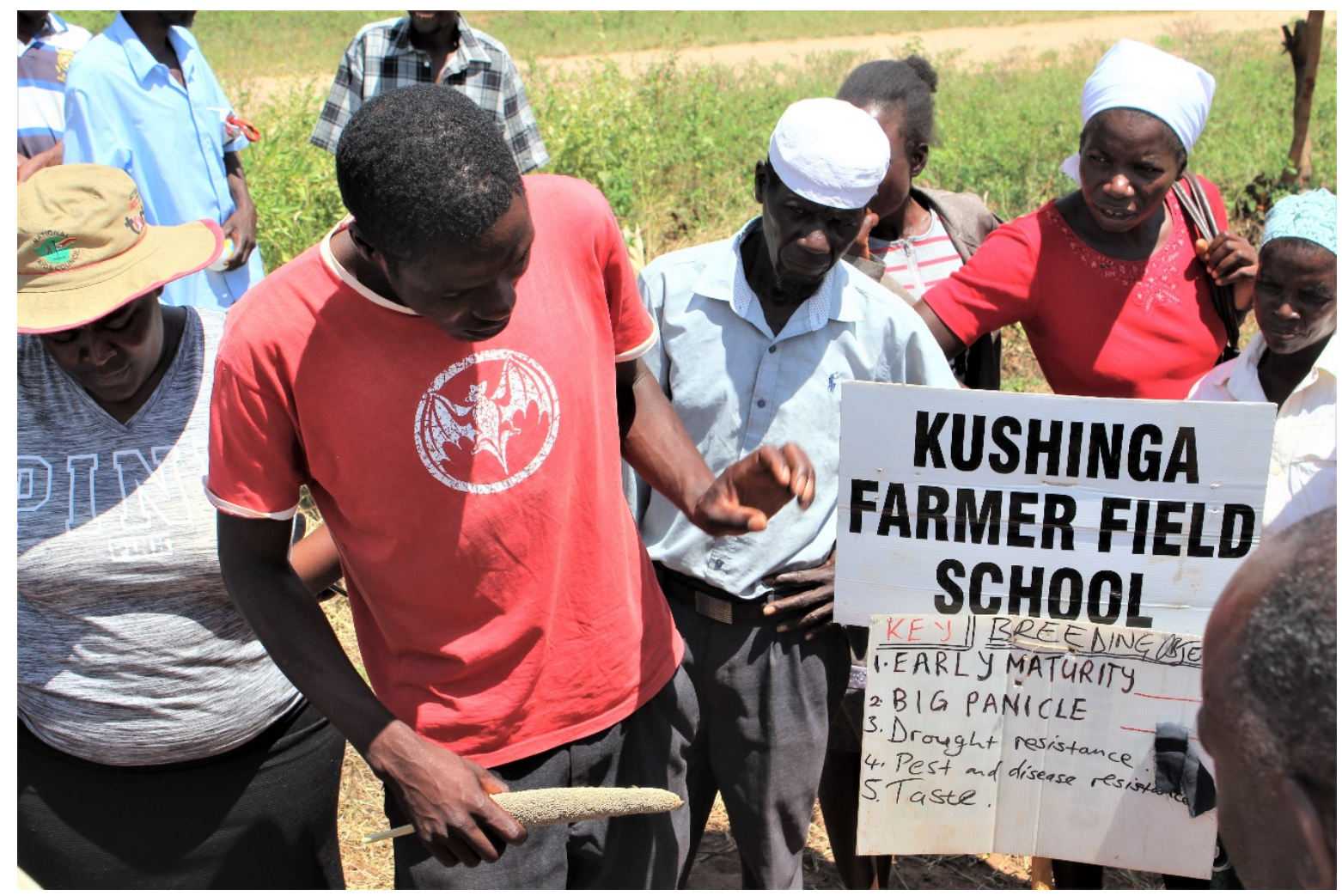

Photo 7: Farmers of the Kushinga FFS explain their millet breeding experiment. Credit: The Alliance of Bioversity International and CIAT/R.Vernooy

For PVS, however, farmers working in their FFS can only manage a sizable number of stable lines, usually up to 10 . The fact that farmers actively participative has enhanced the adoption of varieties released in the communities.

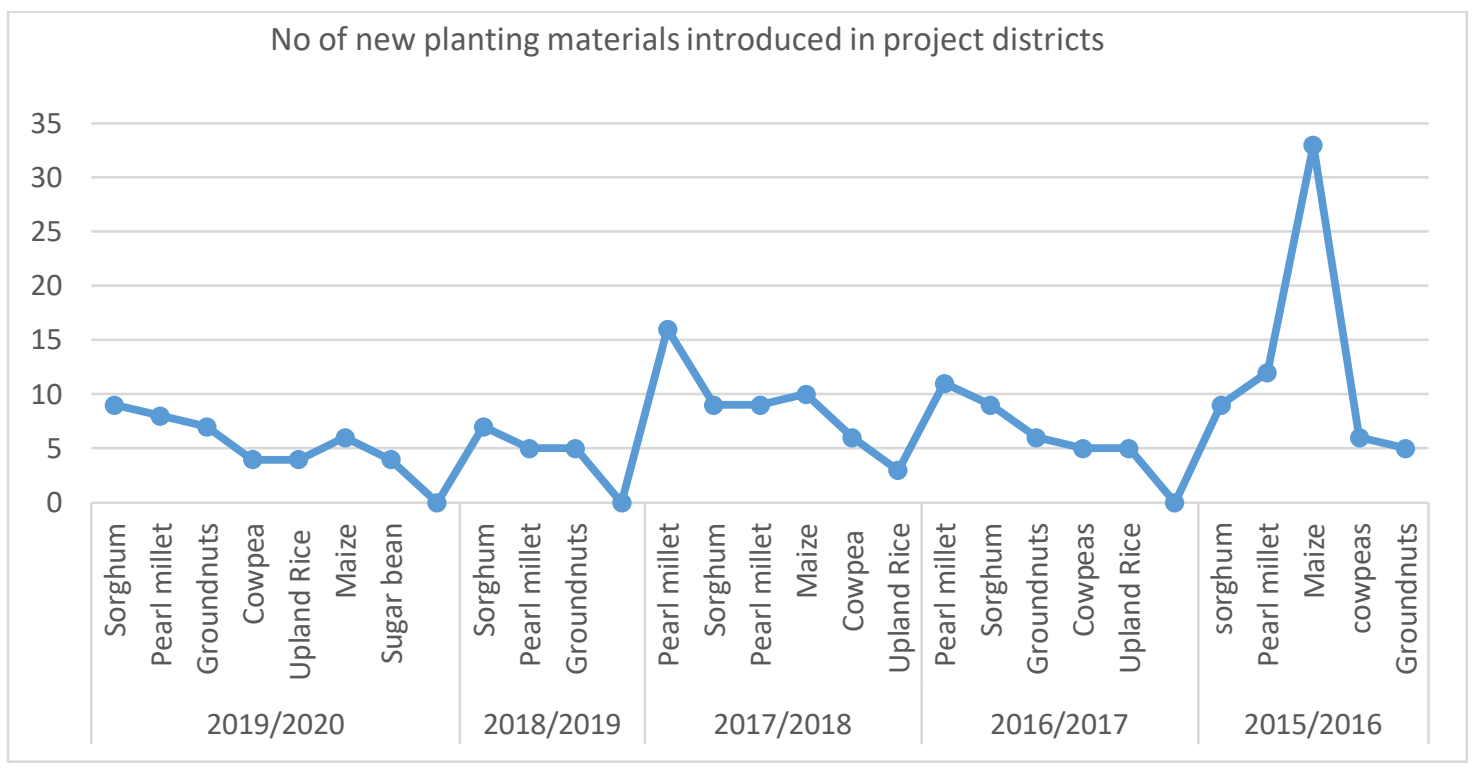

Figure 6: Number of new crops and crop varieties sourced from CGIAR Centers and NARS and introduced in FFS plots 


\section{Participatory Variety Enhancement (PVE)}

Participatory Variety Enhancement is sometimes called variety restoration and is carried out by farmers to "recreate" a local variety that has deteriorated or is no longer coping with the changing climatic conditions. Farmers apply strong positive and negative selection over a period of three seasons. At the end of the season, only the best $10 \%$ of the seeds or panicles are retained for planting in the next season. In the Zimbabwean experience, PVE has led to the recreation old varieties; a process which has resulted in the increase in crop yields of old varieties by approximately $10-30 \%$ after yield trials were carried out at the end of the three seasons of PVE.

In addition, it has also been observed that after enhancement, the ability of the old variety to adapt to changing climatic conditions improves to a great extend. Results coming from the field have shown that PVE is very attractive to farmers working in the FFS, as they do not need any materials from outside (the breeding institutes), but work with their local varieties with the aim of improving them. This gives the farmers a sense of pride.

\section{Participatory Variety Development (PVD)}

PVD is more complex than PVE and PVS. Under PVD, farmers select from within a single and large population of different individuals, called a segregating population. The selection is based on their own breeding objectives. Farmers may choose to cross their own varieties, with the aim of combining qualities of different varieties into a new one. In the context of Zimbabwe, the breeders actually provided the segregating populations.

The selection by farmers in the FFS is usually by mass selection and bulking of preferred individuals and is used in the first generations after a crossing (F1 to F4). At a later stage, pedigree selection may be used. PVD takes a much longer period of time than PVS. In the context of Zimbabwe, it was realised that the FFS can only manage a small number of segregating populations of usually five populations. Just like PVS, PVD also helps to increase diversity in the communities as farmers select from segregating populations based on their breeding objectives. Farmers who mastered PVD demonstrate greater confidence in farming, most notably women participants.

In this process, farmers' selection choices are made based on the changing local climatic conditions; based on CTDT's long experience, it has been observed that breeders do not always come to the same choices -they may have other criteria for trait selection. The farmer-led PVD has also demystified the idea that ordinary farmers cannot do their selections at a high level than PVS.

\section{Gender mainstreaming in PPB/PVS work}

Women make up over $80 \%$ of the active members of the farmer field schools. They are involved in evaluating and selecting the best performing lines and/or new introduced varieties. These women were empowered through training, exchange visits and occupying at least $50 \%$ of the positions on the management committees. Through these activities, some of the women graduated into key leadership positions in local government and politics.

The PPB/PVE work that CTDT and partners has been carrying out has proved to be very important in improving the food and nutrition security status of farmers in project sites, as our observations confirm. It has increased crop diversity at household levels, which is instrumental to improve the chance of getting a harvest, in particular in very low rainfall seasons. Diversification of the crop base has thus contributed to climate change adaptation in project districts. Women are major players in FFS implementation. They are key the true keepers of crop diversity of indigenous vegetables and local cereals and legumes (cowpeas, groundnuts). With climate change, the role of women as breeders has been strengthened.

This has seen women investing more time in PPB, PVE and PVD in a bid to increase crop diversity, which has helped them to improve their food and nutrition security status and to absorb the shocks of climate change. Participatory Variety Selection (PVS), PVE and PVD have contributed to crop diversification in project sites. The FFS hosting these activities have become critical sources of seed. 


\section{Conclusions and lessons learned}

Implementing PVD, PVS and PVE has created stronger linkages between breeders within the NARS and CGIAR centres, and the farmers to share expertise with regard to the importance of these crops and how they relate to climate change and food and nutrition security. The involvement of government partners from research, extension and national gene banks is key for the sustainability of such projects as they provide technical backstopping.

The involvement of traditional and local governance leadership ensures sustainability. Involvement of political leadership contributes to pro-poor policy formulation and implementation.

The strong conviction among conventional breeders that smallholder farmers cannot contribute to the breeding processes is still very strong. While not all farmers can positively contribute to a very long breeding process, breeders should change their mind and adopt participatory approaches to breeding (involve farmers by availing breeding lines at F4, F5 or F6).

Smallholder farmers can greatly contribute to the release of varieties that suit their crop growing conditions. PPB and PVD processes are expensive for both NARS and CGIAR centres, but they are worth investing in. However, resources to carry out PVD, PVS and PVE, are limited. A number of communities that requested support to construct a community seed bank could not be supported, because of financial resource limitations. 


\section{The importance of Community Seed Banks in Zimbabwe: the experiences of Community Technology Development Trust}

Manata Jeko, Sipiwe Mapanda, Patrick Kasasa and Andrew Mushita, Community Technology Development Trust

\section{Background}

Zimbabwe, with an agricultural sector already in serious challenges, is one of the Sub-Saharan countries worst hit by El Niño, a cyclical climatic phenomenon which occurs every 2-7 years. The El Niño effect is characterized by an anomalous rise in the temperature of the central Indian Ocean between December and January. During the years that it has occurred, it has resulted in a significant reduction in rainfall, with serious consequences for agriculture in general and food and nutrition security in particular in the entire region.

The 1992-93 El Niño induced drought was particularly long and intense with a negative impact on crops and livestock, and consequences for millions of people in the sub-region. With the realization that community seed banks could save farmers' agro-biodiversity from being lost in case of similar droughts, Community Technology Development Trust (a NGO) encouraged farmers to build community seed banks in three districts of Uzumba Maramba Pfungwe (UMP), Tsholotsho and Chiredzi. Construction of CSBs has continued over the years and to date, CTDT has established 16 community seed banks in 10 of its 22 operational districts with funding support from a number of partners, in particular Oxfam, Bread for the World (Germany) and a number of funding partners through the Zimbabwe office of the United Nations Development Programme (UNDP).

\section{Problem addressed}

Concerns have been raised in recent years over the increasing loss of plant genetic resources for food and agriculture in Zimbabwe. Crop failures due to climate change induced droughts has resulted in smallholder farmers losing planting materials (seeds and vegetatively propagated materials). The crop failures have resulted in poor or no harvests leading to food and nutrition insecurity among households. Such situations are more pronounced in low rainfall districts of the country, which include CTDT's operational districts. Traditional leaders and smallholder farmers in these districts have raised concerns over the continued loss of local agricultural biodiversity and the traditional knowledge related to processing, utilization and storage of important crops. To curb further agro-biodiversity losses in their communities, smallholder farmers approached CTDT to facilitate the construction of community seed banks.

\section{Theory of change}

Community seed banks ${ }^{2}$ (CSB) provide options for smallholder farming households to conserve, use and exchange seed of local crop varieties. CSBs facilitate the conservation of local seeds through use. The need to establish CSBs has become increasingly evident in light of the severe effects of El Niño, which has resulted in devastating droughts in Zimbabwe. These droughts have had negative impacts on smallholder farmer seed systems resulting in the loss of their crops, but also their seeds and other livelihood means. Community Seed Banks are critical in that they offer opportunities to farmers to conserve their seeds, giving them planting materials in subsequent seasons.

Community seed banks provide options for the conservation of seed of local crops and crop varieties. Community Seed Banking is a key strategy in climate change adaptation as it promotes crop diversification, seed exchanges and sales, generation and exchange of knowledge and information on processing and home utilization.

\footnotetext{
${ }^{2}$ Community seed banks are places of storage where indigenous/local/farmer crop varieties are conserved and managed by community members.
} 


\section{The importance of Community Seed Banks in Zimbabwe}

Farmers highlighted that CSBs offer the following opportunities (photo 8):

- $\quad$ Storage facilities of their seeds from community-based seed production programs

- $\quad$ Storage facilities for germplasm collected from households (household collections)

- Storage facilities for germplasm collected from other areas outside the farmers' locations

- Act as seed distribution points during seed fairs, seed selling/marketing point, farmer training venues.

- Act as centres of knowledge and information exchange especially in areas related to seeds within the community.

- On-farm characterization of farmer saved seed

- Crop improvement by farmers (using PVE)

- Restoration and enhancement of lost diversity

- Seed exchanges during seed and food fairs

- On-farm seed multiplication in plots around the facilities

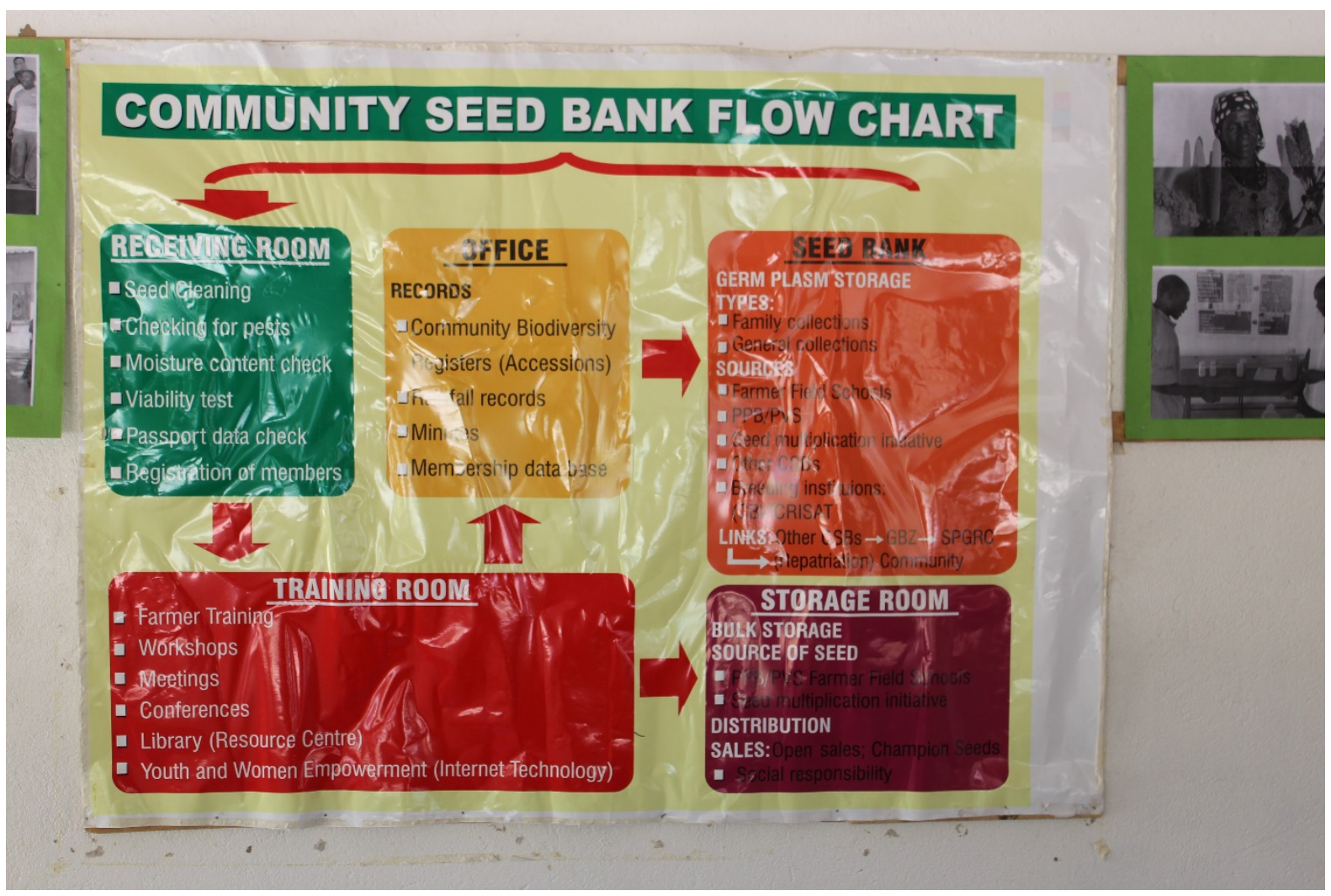

Photo 8: The internal organization of a community seed bank. Credit: The Alliance of Bioversity International and CIAT/R.Vernooy 


\section{Location(s) and actors involved}

The projects are implemented in CTDT's projects sites in Umguza, Nkayi, Murehwa, Murehwa and Uzumba Maramba Pfungwe districts. Except for Murehwa, the rest of the project districts are located in low rainfall agro-ecological regions of the country. In addition, the soils in the project sites are of inherently of low fertility.

The following actors/institutions are involved in the implementation of activities:

- $\quad$ the National Genebank of Zimbabwe provides technical support and germplasm

- departments of Agricultural, Technical and Extension Services (Agritex) provide technical support

- Academic institutions: the University of Zimbabwe-Agrometeorology Group assists designing the research questions, data analysis and interpretation of results

\section{Methodologies used}

CTDT and partners regularly develop survey questionnaires to assess baseline situations, monitor progress and evaluate results, administering and collecting data, analyzing data and writing reports.

CTDT staff asked some of the research questions below. Farmers gave the corresponding answers.

Are you a member of any community seed bank? The majority of woman farmers living within a $5 \mathrm{~km}$ radius from the CSB were members. More elderly women indicated that they were members of a CSB compared to the men and the younger women.

What do you use the community bank for? The majority of the respondents indicated that the CSBs were used as seed storage facilities. Farmers deposited their seeds in rooms designated for general collections or other CSBs rooms referred to as family collection rooms.

List the benefits that you have derived from the CSB in the past 5 years:

- $\quad$ CSBs provided seed storage facilities for farmers.

- $\quad$ CBSs acted as meeting places where farmers exchanged seeds and knowledge during seed and fairs.

- $\quad$ Seed exchanges resulted in increased crop diversity at household levels. The crop diversity contributed to increased adaptation to climate change induced droughts.

- The increased crop diversity contributed to increased food and nutrition security as yields from the wide range of crops increased. The dietary diversity scores in project sites were better than in non-project sites. The same was better in low rainfall compared to high rainfall districts. This could be due to the fact that farmers in the low rainfall districts grow a wide range of crops whereas those in high rainfall districts plant large areas to maize only.

Who makes the decision on what to plant in home gardens and on main crop fields? Men remained the major decision makers on the types of crops to plant in the main fields while women were the decision makers for legumes and vegetables.

How do you see the changes in agro-biodiversity in your locality compared to the diversity 3, 5 and 10 years? Farmers indicated that agro-biodiversity was being lost in their communities compared to 5 years ago. The majority of the respondents were young farmers who were too young to remember the crop types that their parents grew 10 years ago.

Is there any crop type or variety that you abandoned cultivation during the last 5 years? Most of the farmers had abandoned growing traditional rice, because the crop requires a 4-6 months growing period. Farmers highlighted that the rainfall seasons were now short (3-4 months long) and the long season rice varieties cannot reach physiological maturity. 


\section{Seed and food fairs}

Over the past 4 years, a total of 100 seed and fairs were held within CTDT's operational districts. The seed fair events facilitated local seed exchanges, seed sales, exchange of knowledge and information on how to prepare nutritious dishes from products of farmer's seeds (photo 9). Collaboration between CTDT and government staff from ministries of Agriculture, Health, Women and Youth contributed in building the capacities of the farmers in on-farm seed production, preparation of nutritious dishes. In addition, two women from the CSB management committees in UMP were elected into political and local government leadership positions.

The levels of crop diversity within an area can be assessed by considering the number of farmers displaying seed, the number of crops and crop varieties on display; together with farmers, one can then determine whether there is genetic erosion in the community, e.g. through a five-cell analysis.

CTDT encourages communities to organize and hold seed and food fairs within the CSB buildings annually. Over 6000 farmers attend the fairs. The majority of participants are women. Although legal frameworks do not recognize such activities, seed and food fairs are considered positively by the ministry of Agriculture because of their ability to make seeds widely available, which are ordinarily not found in the formal market. The seed and food fairs have resulted in a flow of steady agro-biodiversity.

\section{Gender mainstreaming in community seed banks}

Women play key roles in the conservation and management of plant genetic resources. The majority of them are involved in the collection, exchange, storage and processing of agro-biodiversity for home utilization. Over $70 \%$ of the direct and indirect beneficiaries are of CSB activities are women. These women were empowered through training, exchange visits and affirmative action of reserving at least $50 \%$ of the positions on the management committees to women.

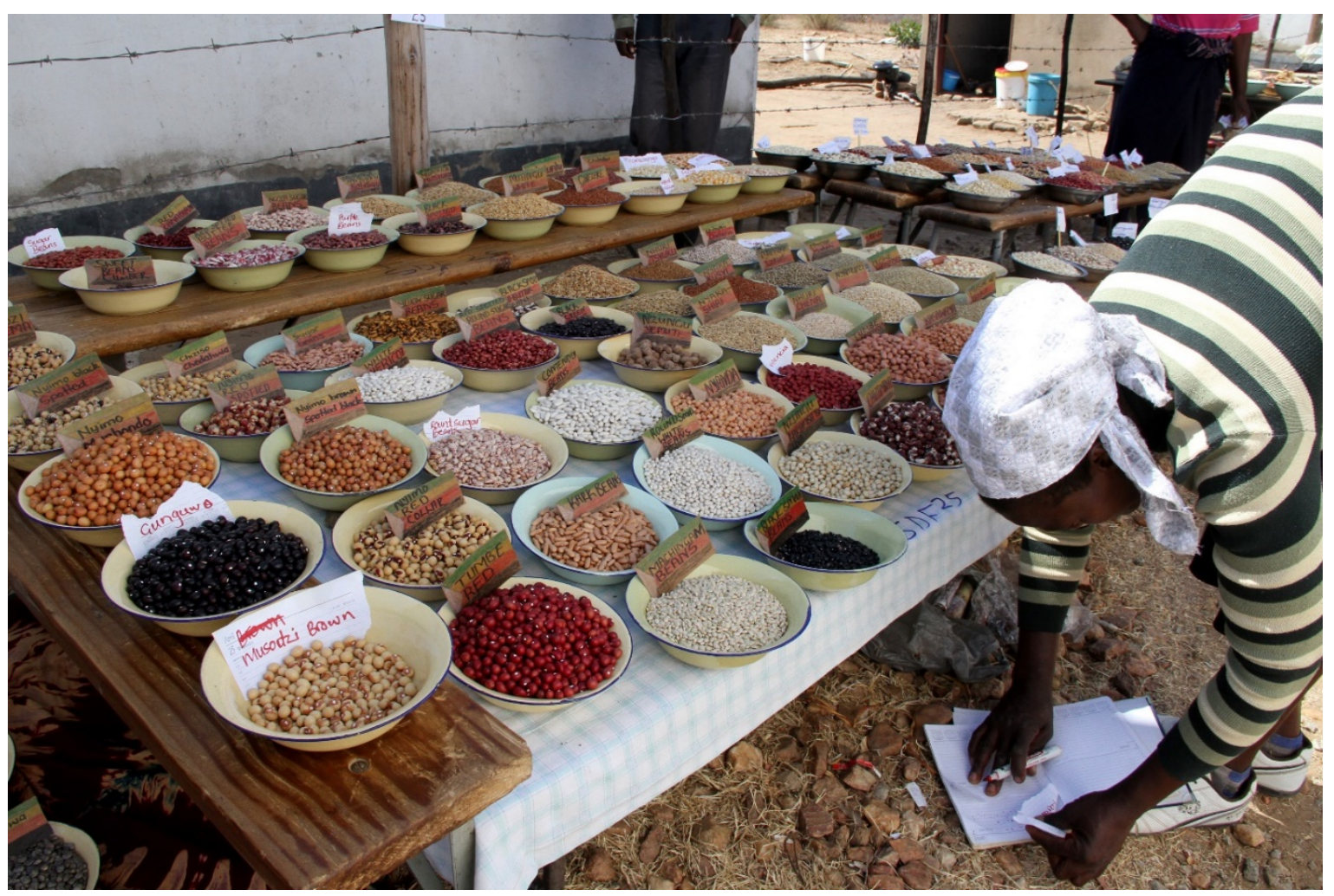

Photo 9: A UMP district woman displays crop diversity from her farm during a seed fair. Credit: CTDT 


\section{Legal and policy issues regarding local seed systems and community seed banks}

Community seed banks provide opportunities for the domestication of the International Treaty on Plant Genetics Resources for Food and Agriculture (ITPGRFA) as they facilitate the conservation, use of PGRFA. With CTDT's support, CSBs have contributed to the realization of Farmers' Rights within its operational districts. The seed bank provides a platform to farmers to save, sell and exchange seed.

Through linkages and cooperation with the national genebank, farmers are able to repatriate lost seeds from the national genebank for rejuvenation and further enhancement on their farms.

There is no specific policy and legal framework providing support to CSBs, but CTDT and partners have initiated discussions on the need for a comprehensive Farmers' Rights legislative framework.

The proposed framework will cover for the establishment of community seed banks interacting closely with the National Genebank and the SADC Regional Genebank.

\section{Results}

\section{Compared to the theory of action/change}

Results from CTDT's field work confirms the theory of changel. CSBs contribute to crop diversification; can be employed as one of the strategies to address climate change adaptation; contribute to seed security, hence food and nutrition security at household level, and support income generation by selling surplus produce.

The farmer seed systems practiced by community seed bankers have a significant impact on (i) crop diversification at the crop and variety levels, (ii) food and nutrition security, especially during drought years, and adaptation.

\section{Major outcomes, constraints and challenges}

Women are major players in the conservation and sustainable use of local plant genetic resources within the households and communities. Most of the seed exchanges, especially of indigenous vegetables and legumes (cowpeas, groundnuts), take place between and among women. With the climate change, the role of women as custodians of seed has been strengthened. This has seen women investing more time to seed selection and conservation in a bid to select varieties which help them to absorb the shocks of climate change.

Community seed banks contribute to the conservation and utilization of local crop diversity. The CSBS have become critical as sources of seed which enables farmers to plant in seasons following droughts. Farmers who have access to community seed bank materials are seed secure at the start of each season.

Implementing CBS activities has created stronger linkages between community seed banks, the national genebank, other civil society organisations and the farmers to share expertise with regard to the importance of plant genetic resources and how they relate to climate change and food and nutrition security.

The rainfall seasons are starting late, are now shorter than what they used to be 10-20 years ago and long dry spells are being experienced during the growing seasons. This is causing poor crop establishment in farmers' fields resulting in crop failure due to poor soil moisture.

Resources to carry out projects such as community seed banking are limiting. A number of communities that requested support to construct CSBs could not be supported because of financial resource limitations. 


\section{Conclusions and lessons learned}

Community Seed Banks have revived the growing of some of those crops that are neglected by government research such as Bambara nuts, sorghum, pearl millet and finger millet in communities where these were disappearing.

Repartition of lost varieties from the National Genebank of Zimbabwe has increased the seed in communities through the engagement of farmers in seed multiplication.

Good collaboration with government institutions is key for the effective implementation of projects including CBSs. The involvement of government partners from research, extension and national genebank is key for the sustainability of such projects as they provide technical backstopping.

Exchange visits with farmers to national and international genebanks contributes to farmer empowerment, knowledge acquisition and improves their understanding of issues relating to challenges with crop losses, and the importance of its conservation through use. CTDT took farmers from its operational districts to the National genebank in Harare and the Southern Africa Development Community Regional Genebank (SPGRC) in Zambia to create awareness.

Women played key roles in the conservation and management of plant genetic resources. The majority of them are involved including collecting, exchanging, storing and processing for utilization almost all the crop biodiversity including some of the Neglected and under-Utilized (NUS) crop species.

Up to $70 \%$ of the participants in the CSB projects are women. In terms of empowerment through training, exchange visits and participation in the seed and food fairs, women play key roles and now occupy key positions in the community seed bank management committee. Through these activities, some of the women graduated into key leadership positions in local government and politics.

The involvement of traditional and local governance leadership ensures sustainability. Involvement of political leadership contributes to pro-poor policy formulation and implementation. 


\section{Constraints to agricultural development: how to maintain soil health and agrobiodiversity? Experiences from Bumula Sub-county, Bungoma, Kenya}

Geoffrey Simiyu and Bernard Wanjala, Sustainable Agricultural Development Initiatives (SADI)

\section{Background}

In Kenya, sugar cane production has been in existence since the 1950s. It was introduced as a major crop to unlock western Kenya's agricultural potential and transform it into the fulcrum of economic prosperity in that part of the country. This study explores the cumulative effects of sugarcane farming and other husbandry practices in the context of income sustainability, versus soil-health and agrobiodiversity in Bumula Sub-county of Bungoma County.

In carrying out this research, the concepts of soil health and agrobioversity were useful to analyze data. Farmers in Bumula Sub-county have for many years been fully involved in sugarcane farming for their economic mainstay through contractual arrangements with either the Mumias or Nzoia Sugar Company. Through this vertical integration of business, the sugar millers focused mainly on increasing the yield per ton of raw canes. This was to be achieved by advising farmers, through the extension service, to apply more mineral fertilizers repeatedly. The additional use of heavy herbicides with residual effects in the soils, practiced together with minimum tillage, was considered to be a way of reducing drudgery for the farmers.

An expansion program to increase the acreage under sugarcane grown outside the nuclei estates targeted farmers with virgin lands. New land was prepared by wanton bush clearing, leading to the encroachment of fragile wetlands and riparian lowlands. The establishment of outgrower companies, namely Mumias (MOCO) and the Nzoia outgrowers company (NOCO), led to increased intensification of sugarcane production with little regard to growing staple food crops by many farmers.

Although national rural development programs, such as the Soil and Water Conservation program, the National Agriculture and Livestock Extension program (NALEP), the National Agriculture Accelerated and Inputs Access Project (NAAIAP) and the current Agriculture Sector Development Support Program (ASDSP) have been in place for many years, their focus has been on a very limited number of crops, in particular maize and bean. None of these programs has promoted crop diversification.

\section{Problem/opportunity addressed}

Sugarcane farming has been the main cash crop in the area and some of the technologies used, such as continued use of mineral fertilizers and herbicides (Sencar, Atrizine, Diuron and Round-up) have had adverse impacts on the environment and the ecosystem (Wood 1985). Other practices contributed to the loss of wild crop species and varieties, i.e. deforestation and burning of cane trashes. Poor soil fertility due to the acidic state has resulted in the decline of crop production and erosion of biodiversity.

Although there have been numerous soil tests and analyses done by various agencies on the sugarcane farms, there has been no proper coordination by an established institution to synthesize all the soil research and share the key results with the farmers.

\section{Research questions to be answered}

1. To find out the causes of low crop productivity in the region

2. To find out the general challenges that farmers face in the region

3. To assess whether the cause of low soil fertility is caused by the use of synthetic fertilizers

4. To identify the efforts made by farmers in the region towards solving the problem of poor soil fertility

5. To look into the roles of women in both food production and sugarcane farming (Bekele 1997)

6. To determine the constraints and choices of commercial and subsistence farming on the status of women 


\section{Theory of action}

The soils are highly depreciated due to the continued use of chemical inputs that have negatively affected crop production in the region. Generally, Bumula sub-county is a net food importer, with nearly ninety percent of the households accessing food from the market centers. The food consists of cereals (largely, maize) and is sourced from Uganda and Trans-Nzoia county of Kenya. Our theory of change is that bio-intensive agriculture can help to rejuvenate the soils in Bumula Sub-county and restore them to their productive potential. In this context, a healthy soil is a precursor of (rich) agrobiodiversity in the environment and the ecosystem. With improved agrobiodiversity, farmers will be able to produce food sustainably, which will contribute to household resilience.

\section{Location and actors involved}

The focal point of study was Bumula Sub-county of Bungoma country, in particular Khasoko and Bumula wards. The sub-county forms part of the expansive southern border of Matungu in Kakamega County and on the far west-side it borders Butula and Teso south of Busia County. Bumula Sub-county has two important agro-ecological zones. According to Jaetzold and Schmidt (1982), an agro-ecological zone (AEZ) is a geographical area which can be defined on the basis of its moisture supply, differences in the soil patterns as well as the associated crops and livestock species the area can raise naturally.

The agro-ecological zone of Bumula Sub-county is the Lower Midland Zone (LM). The seasonal crop calendar here is long (Jaetzold and Schmidt 1982). The altitude in this zone ranges from 1,350-1,500 meters above sea level with annual mean temperature of 22-21 degrees Celsius and annual average rainfall of $1,600-1,800 \mathrm{~mm}$. The first rains normally begin in February and the second rains come towards the end of August.

A large number of crops can be found in this zone (but not on the sugar cane farms) and include: sorghum, sweet potato, soy bean, sugarcane, kales, cabbages, cassava, maize, finger millet, common bean, pigeon pea, cow pea, spider plant, sun-hemp or silver leaf, jute mallow, arrow roots, African nightshades, Bambara nut, groundnut, sesame, okra, pineapple, avocado, passion fruit, watermelon, orange, pawpaw and banana.

The main agricultural actors include the Ministry of Agriculture, Sustainable Agriculture Development Initiatives, and the Mumias Out Growers Company limited, and Nzoia out growers.

\section{Methods and tools used}

Direct observation: It was employed in observing and recording information on cane farming practices from the outset of preproduction to post-harvesting stages. The method served to formulate relevant interview questions. Furthermore, the method was used as a tool to triangulate and evaluate the information given by the informants.

Questionnaire: The interview form (questionnaire) consisted of both open-ended and close-ended questions. In the open-ended questions, the informants responded freely whilst in the close-ended questions, the informants were required to select from a set of categories.

The research investigated methods and practices of sugarcane farming, in particular soil treatment aspects, adoption of modern technology, alternative economic strategies, attitudes concerning food production as well as different crops, and food preferences. The important questions addressed were how these variables affected soil and agrobiodiversity in the role of sustainable food production and economic mainstay.

The study also focused on the status of women both in ascribed and prescribed positions in relation to land use and decision making. The questionnaire instrument was designed after conducting initial archival work and following a prolonged period in the field.

Key informant interviews: This research technique focused mainly on the cane farmers contracted by Mumias and Nzoia sugar companies and other knowledgeable people about commercial farming and farming technologies in the sub-county. They provided information on historical timelines about the beginning of commercial crops in the 1970's. Some of them were young when sugarcane was first introduced. They witnessed how cash crops changed their subsistence world, in many respects resulting in status reversals between men and women (Cattell 1989). 
This cohort of informants provided valuable information concerning the impact of sugar cane growing on soils and biodiversity. Other key informants were those persons involved in agricultural extension services and development and community affairs, such as the Ministry of Agriculture staff, members of the Sustainable Agriculture Development Initiatives (a community Based Organization in Bumula). These informants elaborated on the dilemma of unhealthy soils and poor agrobiodiversity versus sustainable food production in the study area.

Data analysis: The data were analyzed using both quantitative and qualitative methods.

\section{Project research team}

The case study research was conducted by a team of seven researchers, one principal researcher, three male and three female research assistants. Research assistants were familiar with previous sugar cane farming practices in Bumula. In addition, they were conversant with the local social norms, rules and traditions of the communities living in Bumula. All the interviews were conducted in the local languages while English and Kiswahili were only used when interviewing non-resident key informants.

\section{Activities carried out}

The need to have a steady food supply produced by the community itself triggered the formation of Sustainable Agriculture Development Initiatives (SADI), which is a local community based organization. The organization took a central role in the recruitment and mobilization of farmers, with whom the research team worked to promote of crop diversification and organic farming (photos 10-12).

In the beginning, farmers were trained by the Ministry of Agriculture on various typologies of conservation agriculture, bio-intensive agriculture (compositing, soil tillage techniques, cropping systems, integrated pest and disease management, agroforestry, and simple soil testing techniques mainly concerning organic carbon. Various soil and crop husbandry practices, such as crop rotations and zero tillage were employed to incorporate the innovation packages aimed at restoring the soil potential.

Farmers then implemented these technologies gradually by growing different crop types, such as local vegetables, cereals and pulses, during the study period. At each stage or level of operation, data were collected. Parameters for data collection were mainly germination population and amount of inputs applied, and yield per unit area.

Both progressive monitoring and summative follow-ups were used throughout the study period. The collected data from the harvests and descriptive feedback from the farmers on the changes in the yield and restoration of the soil productivity vigor were analyzed and then shared with farmers. Several initiatives were organized to further disseminate the findings.

\section{Results}

From the results, it was noted that there was an improved production in yield due to improved soils. A case is banana, which increased from 6 kilograms to 13 kilograms per bunch. Many farmers gradually embraced the growing of other food crops along sugarcane as a form of diversification to become more resilient against the vicious hunger-pangs amongst many households.

Each household now has nearly $30 \%$ of the crop land under different crops and agroforestry trees. Many farmers are now planting horticulture crops and sell them on the market for income generation. The opening up of small village market joints, where women sell food-wares grown on their own farms, has opened up an alternative source of income as opposed to over reliance on sugarcane income that would previously be earned.

\section{Constraints and challenges}

Although the study resulted in good results and a new hope with regard to soil-health and agrobiodiversity in the sub-county, farmers faced some bottlenecks that portent to water-down the success of adoption rates.

Land rights are still an issue in men-headed households. Women or the youth in this situation have no access to the use of this asset without prior consent from men. 
Ironically, women are generally the beasts of burden of nearly all family chores. Youth have great potential to bring about economic growth by engaging themselves in farming, but this is not happening. If women and the youth would be given more opportunity to make decisions, then the various options to improve soil health would be adopted in a higher percentage.

Many farmers remain indebted financially to the sugar companies and it takes a long time to pay debts.

Availability of material at the initial stage for compositing was a challenge to most farmers; the same as availability of seed, in particular of African leafy vegetables.

Farmer are eager to receive training and become more knowledgeable, but resources are limited.

\section{Conclusions and lessons learned}

The excessive use of synthetic fertilizers and pesticides has had a great impact on soil fertility in the sub-country and restoring the soil and creating a self-sustaining environment require resources and much effort.

Organic farming and crop diversification, and related techniques such as the use of crop residues, composite manure, zero tillage, crop rotations and agroforestry, have a positive impact on improving crop production and generally minimize the cost of production.

Women and youth are more concerned about the soil fertility than men in Bumula. Any development project that aims to address community problems should consider the inclusion of women and youth through affirmative actions.

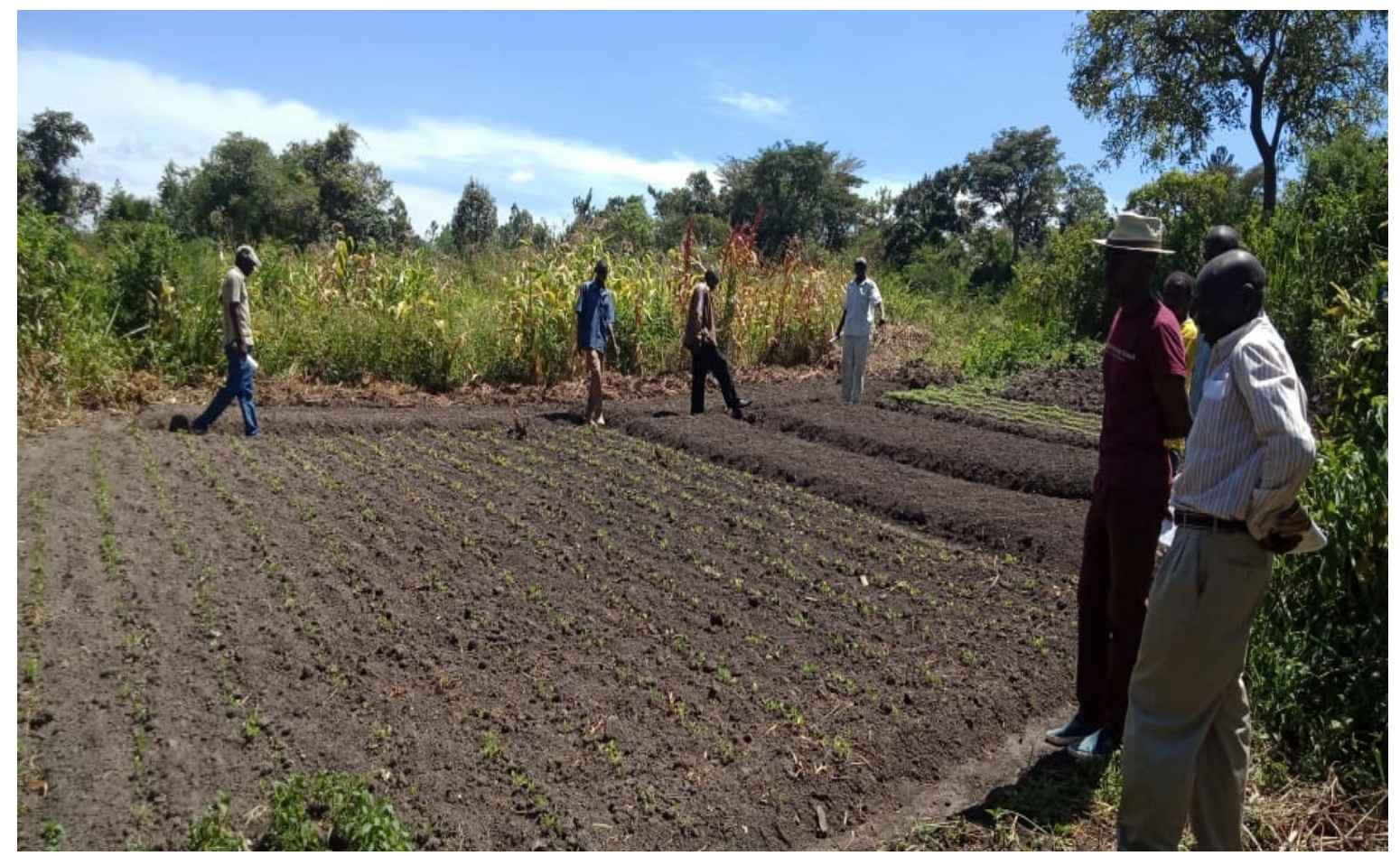

Photo 10: Bio-intensive agriculture involving minimum tillage and organic farming at a demo site in mabusi village (2019). Credit: SADI 


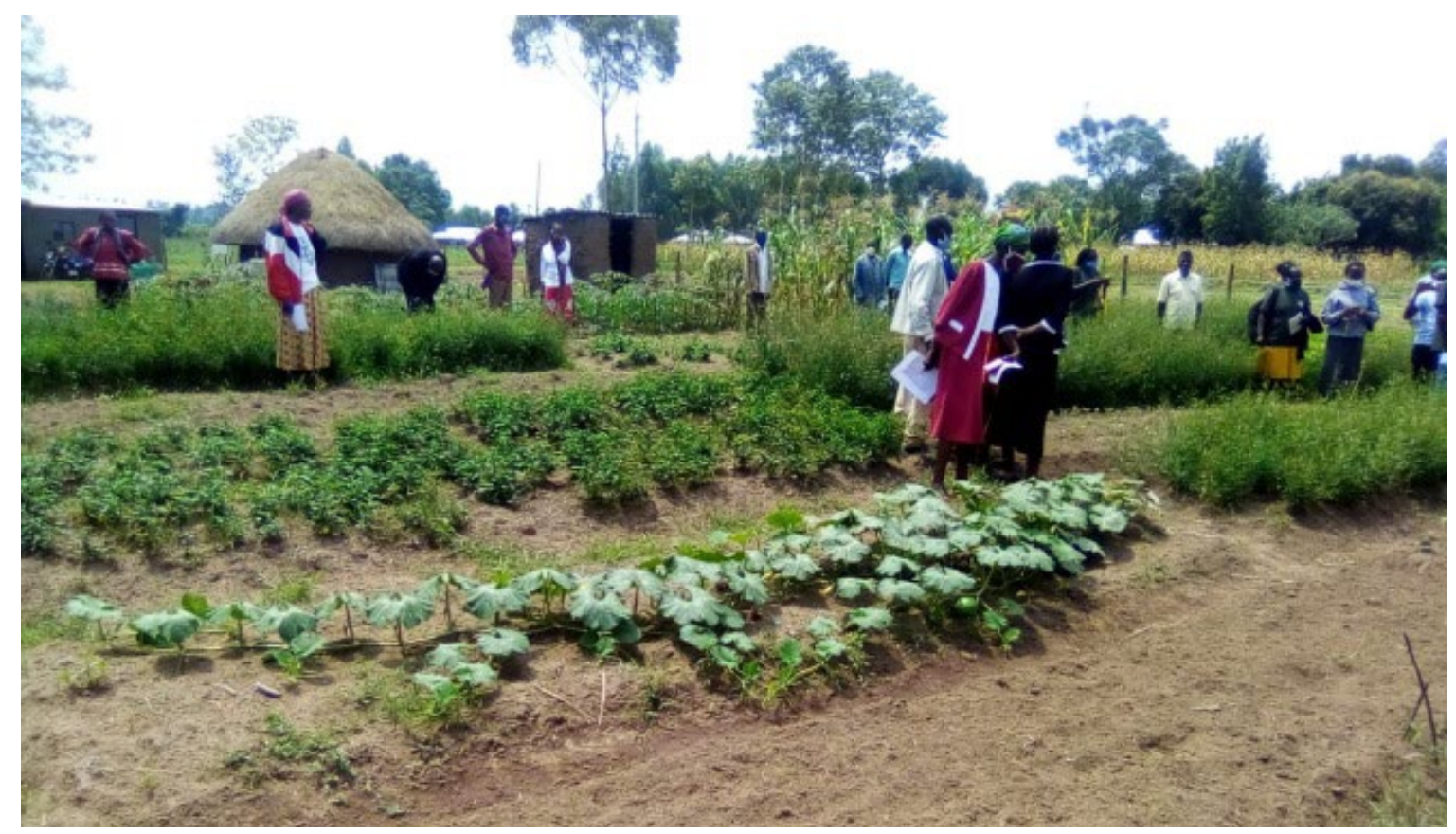

Photo 11: Farmers actively involved in a field day at SADI's demonstration site Lwanda village, about growing African leafy vegetables, orange fleshed sweat potato and maize agrobiodiversity (July 2020). Credit: SADI

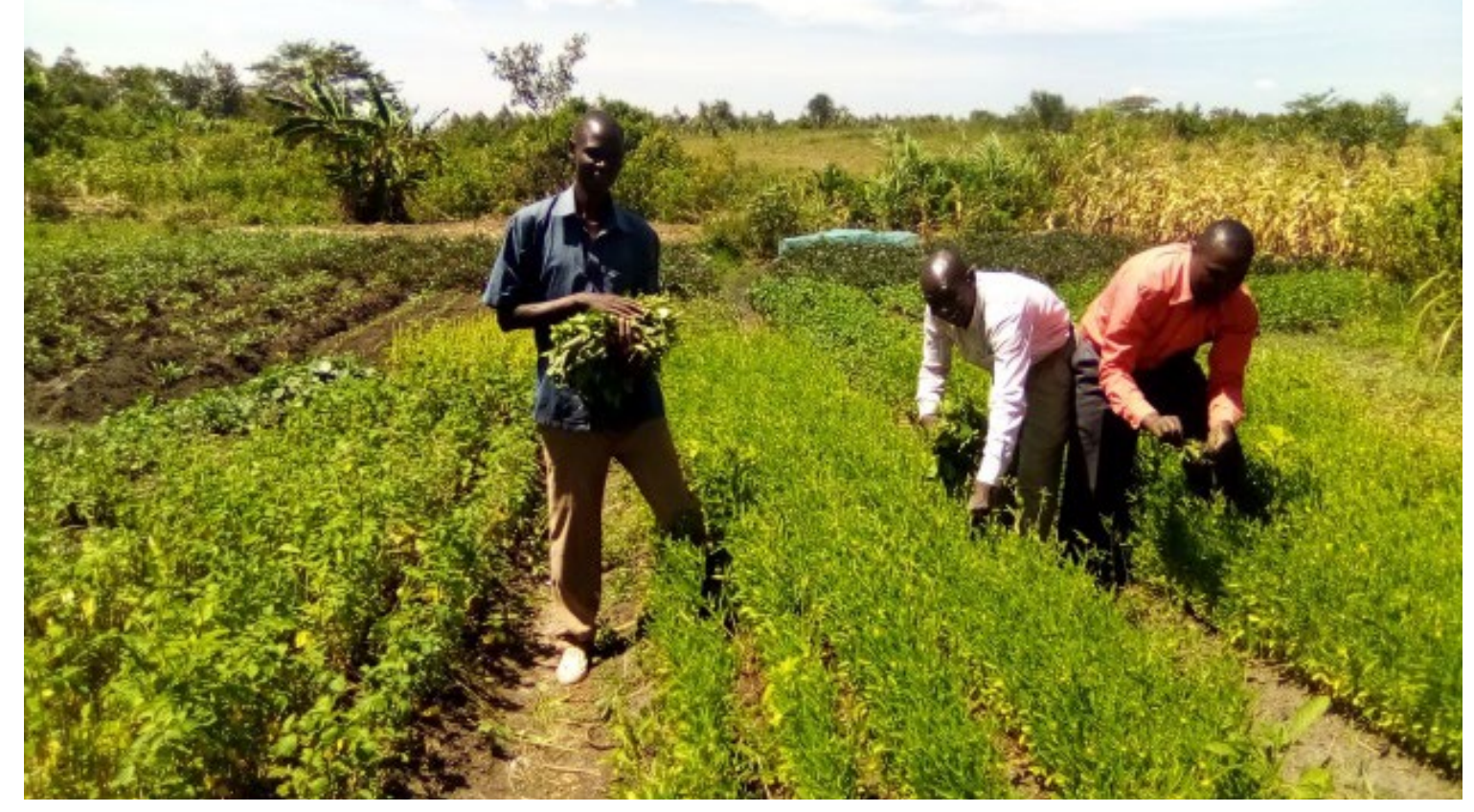

Photo 12: In farmer's field, harvesting of slender-leaf vegetables for sale. In the background, a field of mature maize and sweet-potato (September 2020) 


\section{Acknowledgments}

Special thanks go to all staff from Ministry of Agriculture, Livestock and Fisheries Bumula sub-county for the technical assistance and provision of resourceful information regarding soil status in the area. It will be unfair to forget all sugarcane farmers, key informants and research assistants for giving us the opportunity to learn and for offering a good environment the develop this case study. Heartfelt gratitude goes to the Seed-Savers Network-Kenya (located at Gigil) and the Genetic Resource Research Institute KALRO-GERRI, the national gene-bank, for providing us with the lost heirloom materials, during the upscaling community seedbank project in Kenya, through a grant from Bioversity International that leveraged our efforts. This case study benefitted from the editing by Ronnie Vernooy, the Alliance of Bioversity International and CIAT.

\section{References}

Cattell, M.G. (1989) Old Age in Rural Kenya: Gender, Life Course and Social Change. Ann Arbor, MI: University Microfilms unpublished Ph.D. dissertation.

Bekele, F. (1997) The gender dimension in development projects. Concepts, approaches, and framework for gender analysis. Addis Ababa, Ethiopia: OSSREA.

Wood, A.W. (1985) Soil degradation and management under intensive sugarcane cultivation in north Queensland. Soil Use and Management 1: 120-124.

Republic of Kenya: Ministry of Agriculture Annual report ,2007) Compilation coordinated by Policy and External relations Directorate 


\section{Improving and diversifying planted forages through selection, breeding and inclusion in local production systems -Examples of South-South learning}

M. Peters, S. Mwendia, V. Castiblanco, R. van der Hoek, S. Burkart, S. Douxchamps, U. Ohmstedt and A. Notenbaert

\section{Background}

Livestock based systems provide livelihoods to 1 billion people and account for $40 \%$ of global agricultural gross domestic product. Animal-source foods provide $14 \%$ of the calories and $33 \%$ of the proteins consumed globally and provide essential micronutrients, such as vitamin A, B-12, riboflavin, calcium, iron and zinc. In addition, livestock has high cultural and social values. Producing feed for livestock uses about $84 \%$ of the world's agricultural land (Erb et al. 2007; Foley et al. 2011). The share is even higher in developing countries (FAO 2009). Producing enough animal feed is a challenge, especially in ruminant systems, accounting for 50 to $60 \%$ of the total production costs (Swanepoel et al. 2010). Land resources that can be used for feed production are increasingly constrained.

In the face of climate change and its expected negative impacts on livestock systems, adaptation and increasing the resilience of livestock production systems should be a priority. Regions identified as the most vulnerable, e.g. Sub-Saharan Africa, are also regions where rural communities rely the most on livestock for nutrition security, income and livelihoods. Well-adapted forages with high productivity and nutritional quality can provide animal feed throughout the year while mitigating GHG emissions. They are amongst the most promising innovations in the livestock sector.

The Tropical Forages Program of the Alliance of Bioversity International and CIAT (the Alliance) and its partners contributes to the wide-scale implementation of multiple-win forage interventions. The forages program started working in Africa in the late 1980s, expanding the Latin American Tropical Pastures Evaluation Network (RIEPT, its Spanish acronym) to West Africa under the name of RABAOC (Réseau de Recherche en Alimentation du Bétail en Afrique Occidentale et Centrale). RABAOC was a collaborative research effort between CIRAD-EMVT, ILCA, CIAT and NARS to conduct adaptive research on forage species in humid and sub-humid West and Central Africa.

However, more intensive on the ground presence of the Alliance started only about a decade ago, through the development of a systems approach to forage based crop-livestock-tree systems. That prompted closer interaction with forage improvement through selection and with the breeding of forage grasses of the Urochloa and - more recently - the Megathyrsus genera to target specific lines and their management for Africa. By integrating improved forages in local livestock production systems, the Alliance's tropical forages program explicitly aims to simultaneously enhance livestock production, natural resource use efficiency, biodiversity and climate change resilience, and mitigate GHG emissions.

Tropical forages provide an opportunity to intensify and diversify livestock-crop-tree systems in rainfed environments (with more than four to five months of rain). They could be extended to drier areas if irrigation and/or conservation measures are taken. Until recently, forage production relied on the selection of wild relatives, using only a few species and accessions, e.g. in the case of Urochloa in Brazil 50 million ha are planted to only one cultivar, Brachiaria brizantha cv. Marandu (Jank et al. 2014). For tropical grasses, breeding is more important, most notably for Urochloa spp. (formerly Brachiaria), Megathyrsus maximus (formerly Panicum maximum) and Cenchrus purpureus (formerly Pennisetum purpureum). 


\section{Theory of action/change}

The aim to simultaneously diversify and intensify existing systems relies on using enhanced diversity through either breeding and/or selection, targeting specific production niches, increasing at the same time productivity and water use efficiency, avoiding soil degradation and reducing GHG emissions per unit livestock product. The intensification of systems can create opportunities for scaling forages in partnership with both the public and private sectors. Specific benefits for women and youth exist in terms of reducing time to source feeds and developing small-scale business opportunities, such as the multiplication of planting material, and production of hay, silage or fresh fodder, and forage sales. In Africa, the Alliance currently focuses on a few selected countries where there is a defined and increasing demand for improved forages, and where intensified systems are solidly linked to growing markets for animal-source foods (Coulibaly 2009). These countries are Benin, Ethiopia, Kenya, Madagascar, Mali, Nigeria, Rwanda, Tanzania, Uganda, Zambia, and Zimbabwe. Further scaling to other Sub-Saharan African countries is expected in the near future.

\section{Methodology}

The key methodological approaches employed are:

- Identification of target production areas and markets in West and East Africa through foresight, ex-ante assessments and spatial analyses

- From genebanks to improved hybrids: a multidisciplinary path to deliver genetic gain

- Assessment of local adaptation and promotion through multi-locational trials addressing constraints in forage seed supply systems

- Quantification of environmental impacts and trade-offs/synergies

- Use of social and gender analysis to understand gender-disaggregated barriers and to develop incentives for wide-scale adoption

- Identification of business opportunities around cultivated forages and forage seeds

- Engage in awareness creation and capacity building through media, traditional and digital extension and outreach

- Engagement in policy-making processes to support the adoption of forages and efforts for sustainable intensification

\section{Results}

\section{Identification of target production areas and markets in West and East Africa through foresight, ex-ante assessments and spatial analyses}

A study by Schiek et al. (2018) defined the role of forages to close the gap between rising demand for livestock products and sustainable production. For all but the lowest levels of adoption and production increases, improved forages have the potential for positive return on investment. A more focused scaling scan analyzing possibilities for adoption in Kenya, Uganda and Ethiopia confirmed this potential; work on reaching 100,000 forage users in four years is in progress (Notenbaert et al., unpublished). Notenbaert et al. (2018) applied a suitability mapping tool to the case of tropical forages in Rwanda, Ethiopia, Tanzania, Kenya and Vietnam.

Although different forage crops have various reactions to climate change, in general, a negative impact of climate change on forage crops was projected. Smallholder dairy farmers in Kenya, Tanzania, Rwanda and Ethiopia used these maps for selecting context-specific no-regret forage species and varieties (Mwendia et al. 2019).

The maps also point to the gaps and opportunities for improving and expanding the choice of adapted forage options. This can then be translated to breeding objectives and forage breeding and selection programs can help future generations of farmers by developing a more diversified portfolio of germplasm suitable to future climate conditions. 


\section{From genebanks to improved hybrids: a multidisciplinary path to deliver genetic gain}

The identification of the multiple uses and alternatives offered by the diversity hosted in genebanks is a challenge. When trying to use promising accessions in agroecosystems, challenges are how to deal with diverse abiotic conditions and (new) pests and diseases. In the context of climate change, extreme abiotic conditions are expected to worsen, which demands the selection/breeding of more tolerant cultivars. Forage breeding allows combining in the same cultivar different desired characteristics. Over time, forage breeding evolved from answering fundamental questions of basic biology (1970s), to establishing an appropriate breeding scheme in which apomixis rather than being a barrier to reproduction became an advantage to the stability, multiplication and dissemination of the hybrid (1980s) (Figure 7).

Combining multiple rounds of crosses of recombination and selection, Mulato, the first Urochloa hybrid launched worldwide, reached the market in 2001. Papalotla now commercializes the grass hybrids developed by the Alliance in 72 countries, with over 1 million hectares planted, as indicated by seed sales.

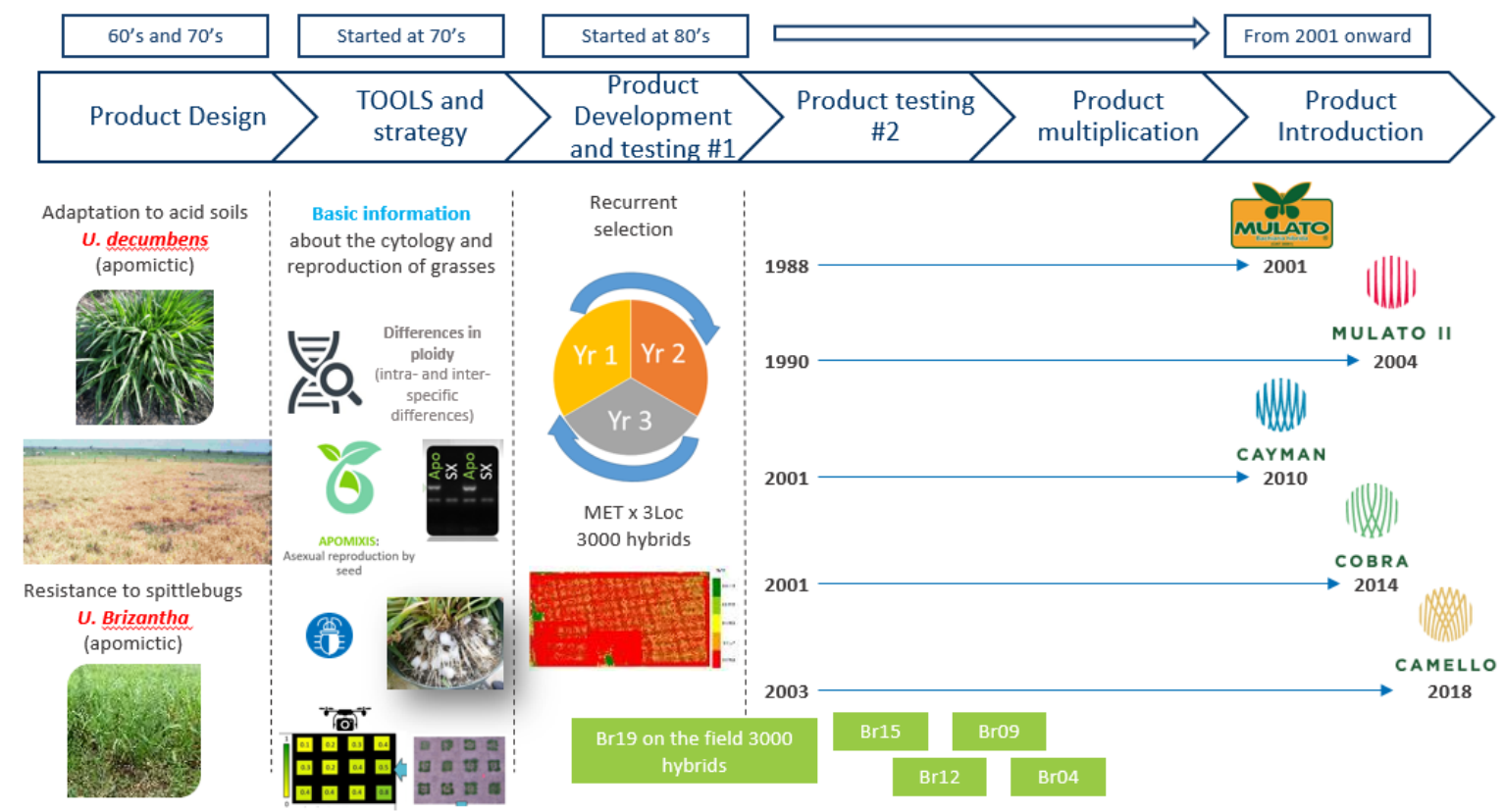

Figure 7: Variety development process for Urochloa (syn. Brachiaria) employed by the Alliance

It is now easier to confront new challenges, such as emerging pest and diseases. For instance, in Eastern Africa, spidermite (Tetranychus urticae) has been found affecting Urochloa. Hybrids with tolerance to spidermite need to be developed targeting a potential market of close to 2 million ha.

\section{Assessment of local adaptation and promotion through multi-locational trials}

Due to the heterogeneous nature of livestock production systems (given temporal and spatial agroclimatic attributes), the most effective selection and targeting strategy is to subject identified forages to real conditions through participatory engagement of livestock producers.

Efforts across several countries in East Africa (e.g. in the southern highlands of Tanzania and in Rwanda), resulted in several good performing forage technologies in terms of high yield and acceptability to livestock producers. In western Kenya, evaluation of Urochloa hybrids and cultivars revealed a performance gradient showing differences within a species.

In Ethiopia, Urochloa hybrid Mulato II yielded highest at low, medium and high altitudes compared to other Urochloa accessions (Adnew et al. 2019), asserting the need to match forage germplasm to the local environment. 


\section{Addressing constraints in forage seed supply systems}

Seed is one of the most crucial elements to meet demand for forages, both for bred materials as well as selections. A sustainable seed system will ensure that high quality seeds of a diversified range of suitable forage are accessible, available in time and affordable to farmers and other stakeholders. The need to support the forage seed sector has been identified by many stakeholders as an important bottleneck (Njarui et al. 2017; Assefa et al. 2017). The development of business models for economically sustainable seed production (including vegetative propagation) and marketing requires concerted action at both demand and supply levels, to ensure a minimum market security for forage seed producers and distributors.

The Alliance is supporting a reliable seed distribution network involving public-private partnerships and incorporating international, national and local seed suppliers. For the hybrids originating from its breeding program, the Alliance collaborates intensively with the private sector partner Papalotla/Tropical Seeds. Sizeable quantities of seed are made accessible and combined with awareness creating activities. Import and distribution of seeds led by Tropical Seeds is complemented by supporting small- to medium-scale businesses in the distribution of vegetative planting material.

Business opportunities for small-scale seedling producers are identified and training provided to strengthen agronomic and business skills. NARS support National Performance Trials (NPTs) and certification/registration processes of new promising forage varieties. While for tropical grasses there is defined interest of the private sector to engage, this is still more limited for tropical legumes, the latter with a few exceptions relying much stronger on propagation and dissemination through e.g. farmer to farmer distribution, development actors and small to medium scale business involving farmers through contract farming.

\section{Quantification of environmental impacts and trade-offs/synergies}

Despite the opportunities and benefits that increased livestock production could bring, it is widely observed that livestock systems are key drivers of global environmental degradation (Foley et al. 2011). Efforts to maximize production and profitability need to be balanced with long-term sustainability and environmental stewardship. It is therefore important to assess potential environmental impacts before embarking on large-scale development projects geared towards livestock production intensification and value chain transformation (Notenbaert et al. 2020).

Alliance researchers developed an indicator framework for ex-ante assessments of environmental impacts of development interventions in livestock VCs, i.e. the Comprehensive Livestock Environmental Assessment for improved Nutrition, a secured Environment and sustainable Development (CLEANED). It estimates biomass, water and nutrient flows and assesses three dimensions of environmental impacts across different spatial and temporal scales: (1) water use, (2) soil health and (3) greenhouse gas emissions. The CLEANED framework is intended to support decision-making and help prioritizing the development actions of governments, donors, NGOs and farmer organizations in data-scarce environments (Notenbaert et al. 2014).

The application of the CLEANED tool to the dairy VC in Tanga, Tanzania (Notenbaert et al. 2020), revealed that milk production increases associated with the introduction of improved feeding strategies are projected to go hand-in-hand with increases in land requirements for feed production and associated increases in absolute soil loss. Under unchanged fertility management systems, it would result in an increasing negative $\mathrm{N}$ balance. The land productivity ( $\mathrm{kg} \mathrm{FPCM} / \mathrm{ha}$ ) is, however, expected to increase. In the mixed crop-livestock systems, the absolute total water use is expected to increase due to larger feed requirements. The water appropriated per unit of milk would decrease. The animal herds with bigger and more productive animals are estimated to cause higher GHG emissions.

\section{Use of social and gender analysis to understand gender-disaggregated barriers and incentives for wide-scale adoption}

Rough estimates indicate that the economic benefits of improved forages outweigh the costs. Ready markets are available for many inputs and outputs, save for lack of seeds and low prices for milk. Access to credit remains a big challenge with negative consequences for adoption, as is the access to capacity 
building measures. Our research indicates that most farmers are motivated to adopt improved forages because of their tangible benefits.

Amplifying and demonstrating such advantages to farmers would therefore promote adoption. Oulu et al. (2020) analyzed factors that influence the adoption of improved forage varieties in Western Kenya. The results indicate that the choice of which variety to recommend for adoption is complex depending on physiology and genetics, agroecological conditions, agronomic practices, knowledge and skills of the farmers, costs and benefits, availability of resources and challenges with existing forages.

While some aspects can rely on perceptions of farmers and other stakeholders, some can only be conclusively determined through field trials and assessments addressing forage production as well as effects on quantity and quality of milk.

Results indicate that improved forages are mostly superior to local ones, e.g. in terms of increased milk production, nutrition/protein content and disease resistance. However, traditional forages have attributes that complement improved ones. This explains why most farmers who have adopted improved forages also retain traditional forages.

A portfolio approach that promotes the adoption of diverse improved forages with the retention of some of the existing traditional forages is thus recommended and pursued to enhance resilience to climatic and other shocks while promoting agrobiodiversity (photo 13 ).

Gender influences adoption in many ways, with men still key decision-makers even though a more nuanced understanding of the soft power of women is important. Group membership enhances adoption due to informational and other benefits.

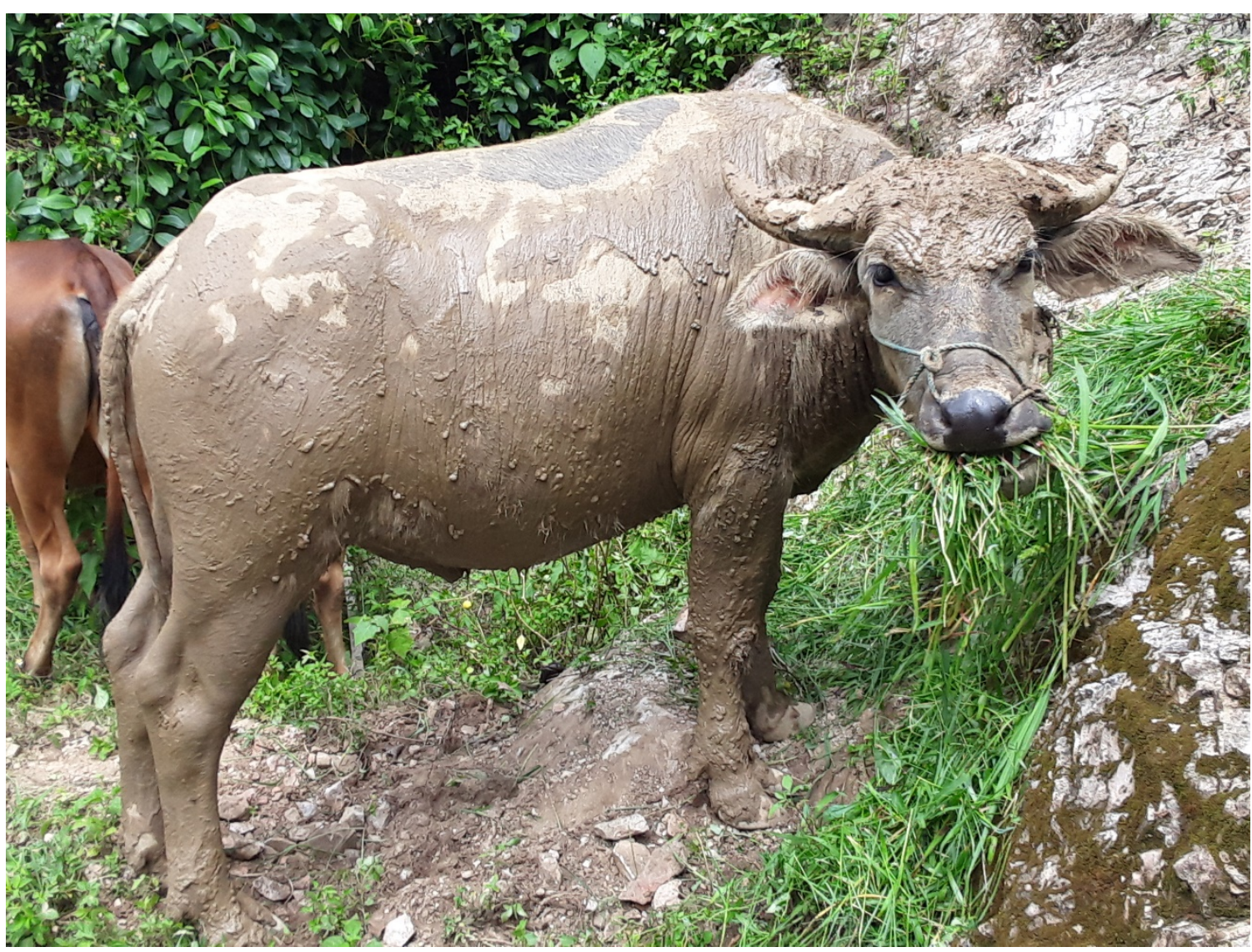

Photo 13: A buffalo enjoying a forage meal in Vietnam. Credit: The Alliance of Bioversity International and CIAT/M.Otieno 

seeds

Like other crops, forages present potential business opportunities along the value chain: sale of forage seeds, seedlings, vegetative splits and forage products, e.g. hay (Mwangi and Onyango, 2019), but also end product differentiation and price premiums (e.g. sustainable beef). Businesses in turn spur market pull, catalyzing adoption and scaling.

\section{Engage in awareness creation and capacity building through media, traditional and digital extension and outreach}

In order to get forages to be used at scale, awareness creation and capacity building, especially for the smallholder dairy producers, are needed (Mwangi and Onyango 2019). Usually, farmers acquire information through various sources and modes; efforts that incorporate multiple outreach approaches are more likely to have greater reach, e.g. field days, radio and television programs, ICT platforms and farmer visits. Digital extension services should be expanded, and capitalize particularly on the lessons learned due to the COVID-19 contraction of traditional face-to-face extension.

\section{Engagement in policy-making processes to support the adoption of forages and efforts for sustainable intensification}

Engagement in policy-making processes is crucial to support the adoption of improved forages and sustainable intensification. Our experience from Latin America, in particular Colombia, shows that contributing to multi-stakeholder platforms or sector roundtables with scientific advances helps in validation and awareness creation. It also enriches facts-based public policy-making processes, private sector initiatives along the value chains (e.g. capacity building, development of sustainable products), the development of particular value chain services (e.g. credit schemes for investments in forages) and dialogue among a broad range of actors. Scaling can be realized through linking such national level efforts to international sector platforms and initiatives, such as the Global Roundtable for Sustainable Beef or the Global Agenda for Sustainable Livestock.

\section{Prospects}

Demand for planted forages is rapidly increasing, with an estimated 30,000 to 35,000 farmers currently having adopted planted forages and a target of 100,000 adopters over the next four years in Eastern Africa, for example. The increased demand for improved forages is due to higher productivity, higher quality and prolonged survival in the drought period, in this combination mostly not available in comparison to forage alternatives currently employed at farm level.

In many regions of the world, planting forages is only recently emerging e.g. Sub-Saharan Africa and parts of Asia. To respond to new social, economic and environmental challenges, a system's change is needed. This includes maintaining a portfolio of currently used forages, exploring the diversity of forages - e.g. grasses in tropical Africa and legumes in tropical Americas and Asia - in their center of origin and amplifying the diversity of forage options through introduction of germplasm selected from wild relatives and breeding.

To be successful, this will require parallel work on the sustainable management of forages to build the much needed capacity. Forage conservation (e.g. silage, hay and densified forages) will play an increased role as land resources decrease and vulnerability increases. Thus, in summary, diversity in plant genetic resources will need to go hand in hand with diversification and intensification of management. 


\section{References}

Adnew W; Tsegay BA, Tassew A; Asmare B (2019). Effect of harvesting stage and altitude on agronomic and qualities of six Brachiaria grasses in North Western Ethiopia. AgroLife Scientific Journal. Volume 8: 9-20

Assefa G; Ledin I (2001). Effect of Variety, Soil Type and Fertiliser on the Establishment, Growth, Forage Yield, Quality and Voluntary Intake by Cattle of Oats and Vetches Cultivated in Pure Stands and Mixtures. Animal Feed Science and Technology 92(1-2): 95-111

Coulibaly D (2019). Evaluation des performances technico-économiques des cultures fourragères dans la région de Sikasso. Rapport d’Etude, préparé pour ILRI dans le cadre du projet Feed the Future Mali Livestock Technology Scaling Program

Erb KH; Gaube V; Krausmann F; Plutzar C; Bondeau A; Haberl H (2007). A comprehensive global 5 min resolution land-use data set for the year 2000 consistent with national census data. Journal of Land Use Science 2: 191-224

FAO (2009). The state of food and agriculture: Livestock in the balance. FAO (Food and Agriculture Organization of the United Nations), Rome. (Retrieved $23^{\text {rd }}$ of November 2020 from http://goo.gl/RRpE5)

Foley JA; Ramankutty N; Brauman KA; Cassidy ES; Gerber JS; Johnston M; Mueller ND; O'Connell C; Ray DK; West PC; Balzer C; Bennett EM; Carpenter SR; Hill J; Monfreda C; Polasky S; Rockström J; Sheehan J; Siebert S; Tilman GD; Zaks DPM (2011). Solutions for a cultivated planet. Nature 478: 337342

Jank L, Barrios SC, Do Valle CB, Simeao RM; Alves GF (2014). The value of improved pastures to Brazilian beef production. Crop and Pasture Science 65: 1132-1137

Mwangi DM; Onyango E (2019). Innovations for Agricultural Productivity (IAP) Kenya - Improvement of the Dairy Value Chain. Fodder Value Chain Analysis in Western Kenya : Opportunities for Business Development Kisumu, November 2019. A Report. Deutsche Gesellschaft für Internationale Zusammenarbeit (GIZ) GmbH, Bonn

Mwendia S; Mwilawa A; Kizima A; Bwire J; Nzogela B; Mutua J; Notenbaert A. (2019). Forage Options for Tanzania Southern Highlands: Preliminary Assessment. In: TropenTag 2019, September 18-20 2018, Kasel, Germany

Njarui DMG; Gatheru M; Gichangi E; Nyambati EM; Ondiko CN; Keziah W (2017). Determinants of Forage Adoption and Production Niches among Smallholder Farmers in Kenya. African Journal of Range \& Forage Science 34(3): 157-166

Notenbaert A; Lannerstad M; Herrero M; Fraval S; Ran Y; Paul B; Mugatha S; Barron J; Morris J (2014). A framework for environmental ex-ante impact assessment of livestock value chains, 6th All Africa Conference on Animal Agriculture, Nairobi, Kenya, 26-30 October 2014

Notenbaert AM; Mutua J; Mwendia S; Mukiri J (2018). Mapping the suitability of tropical forages - now and in the future. In: Tropentag 2018 September 17-19, 2018 Ghent, Belgium

Notenbaert, A., Groot, J.C., Herrero, M. et al. (2020). Towards environmentally-sound intensification pathways for dairy development in the Tanga region of Tanzania. Regional Environmental Change 20 (138). https://doi.org/10.1007/s10113-020-01723-5

Oulu, M; Notenbaert, A. (2020) Adoption of improved forages in Western Kenya: Key underlying factors. [Presentation done November 24, 2020]. The Alliance of Bioversity International and CIAT, Rome. https://hdl.handle.net/10568/110543

Schiek B; González C.; Mwendia S.; Prager SD (2018). Got forages? Understanding potential returns on investment in Brachiaria spp. for dairy producers in Eastern Africa. Tropical Grasslands-Forrajes Tropicales 6(3): 117-133

Swanepoel F; Stroebel A; Moyo S. (2010). The Role of Livestock in Developing Communities: Enhancing Multifunctionality. Co-published by The Technical Centre for Agricultural and Rural Cooperation (CTA) 


\section{Final reflections}

Ronnie Vernooy

The case studies in this working paper present very diverse, but effective pathways of crop diversification and report various positive results and related improved knowledge and skills, e.g. about the multiple functions of biodiversity, management of pests and diseases, soils, water and crops. The cases clearly demonstrate how crucial and valuable agrobiodiversity (including crops, trees and livestock) is for rural livelihoods and economies at large.

The studies are based on long-term field research in close collaboration with farmers, their communities and organizations (e.g. Farmer Field Schools, community seed banks) and other stakeholders. Another key feature is that the cases use different system approaches, which go beyond just the production side of farming. Such approaches are instrumental to analyze the dynamics of farming and the linkages that are required to practice sustainable agriculture and contribute to positive livelihood outcomes. The table presents the main benefits across the case studies.

\section{Benefit}

Enhanced awareness about functions and benefits of crop diversification

Increased technical skills and knowledge

Enhanced soil fertility and health

Reduced pest and disease pressure

Increased ecological redundancy

Mitigate GHG emissions

Increased productivity

More marketing opportunities

Increased income

Increased food supply/security

Improved nutrition/diets

Reduced poverty

Increased seed security

Strengthened social cohesion

Increased adaptive capacity to climate

change

Increased resilience

Multiple and simultaneous benefits

\section{Case study}

Mali, Burundi, Kenya

Mali, Burundi, East Africa, Kenya, Zimbabwe

Kenya, Forages

Mali, Kenya, Zimbabwe

Mali, Forages

Forages

Mali, Burundi, East Africa, Kenya, Zimbabwe, Forages

Mali, East Africa, Kenya, Zimbabwe, Forages

Mali, Kenya, Zimbabwe, Forages

Mali, Burundi, East Africa, Kenya, Zimbabwe

Mali, Burundi, Zimbabwe, Forages

Mali, Forages

Mali, Burundi, East Africa, Zimbabwe

Mali, Zimbabwe

Mali, Burundi, East Africa, Zimbabwe, Forages

Mali, Kenya, Forages

Mali, Burundi, East Africa, Kenya, Zimbabwe, Forages

diversification identified in the case studies

The case studies show that there is a relatively clearly "visible" causal relationship between crop diversification and diverse positive livelihood outcomes listed in the table, but they are not indicative let alone conclusive about increased resilience, although the Kenya, Mali and forages cases state it has been a result there. However, very concrete indicators are not given.

Building on a recent literature review on the same topic of crop diversification and resilience (Vernooy, forthcoming), we can offer some reasons why it is not so easy to provide practical evidence for all the steps of the theory of crop diversification change. The key findings of the literature review allow to diagnose that the cases in this working paper have some shortcomings in terms of theory (of action/change) and methodology.

Conceptually, there appears to be a need for a more nuanced and elaborated theory of action/change that links (the choice of) particular crops to a particular diversification strategy to livelihood outcomes and then to strengthened adaptive capacity and to resilience (as a stepwise process). In the first part of the pathway, this implies demonstrating how better access to crop varietal diversity (from diverse sources) provides farmers with an opportunity to more effectively diversify and/or sustainably intensify their production, management, harvesting, and marketing of derived products in space and over time. Making use of more and better quality crop diversity ultimately benefits natural resource management, household consumption, nutrition, and health. 
In the second part of the impact pathway, the combined improved livelihood outcomes can lead to an increased capacity to foresee and deal with shocks, e.g. by distributing farming uncertainties and risks over space and time. Thus, resilience is constructed or emerges through the aggregation of two or more mutually-reinforcing livelihood outcomes.

Methodologically, improvements can be made in terms of a more detailed analysis of the baseline situation (e.g. crop/variety diversity index, level of seed security, diet composition or food intake, income sources and levels, level of exposure to climate shocks, level of exposure to market shocks); and in a more systematic evaluation of results compared to the baseline situation. Five steps are proposed:

Step 1: Identifying farmers' goals, including a gap analysis of functional diversity in the current farming system.

Step 2: Assessing current and future climate-related production risks.

Step 3: Assessing enabling and disabling factors.

Step 4: Designing the crop diversification strategy to include impact pathway and expected outcomes.

Step 5: A Theory of Change-based evaluation.

We refer to the literature review for more details (Vernooy, submitted for review).

\section{Reference}

Vernooy, R. Does crop diversification lead to climate-related resilience? Improving the theory through insights on practice. Submitted for review. 
Mobilizing crop diversity for climate change adaptation and resilience: field experiences from Africa

ISSD Africa Working Paper, September 2021 ISSD Africa 2021-03
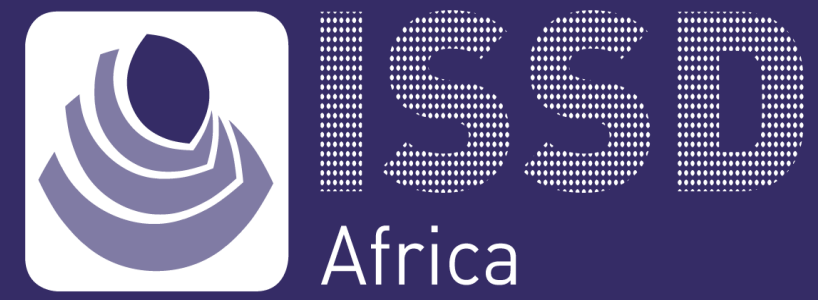